\title{
Investigation of the Effects of Surrounding Media on the Distributed Acoustic Sensing of Helically-Wound Fiber-Optic Cable with Application to the New Afton Deposit, British Columbia
}

\author{
Sepidehalsadat Hendi ${ }^{1}$, Mostafa Gorjian ${ }^{1}$, Gilles Bellefleur ${ }^{2}$, Christopher D. Hawkes ${ }^{3}$, Don White ${ }^{2}$
}

$5{ }^{1}$ Geological Engineering, Department of Earth, Ocean and Atmospheric Sciences, University of British Columbia, Vancouver, BC, Canada

${ }^{2}$ Geological Survey of Canada, 601 Booth St., Ottawa, ON, Canada

${ }^{3}$ Geological Engineering, Department of Civil, Geological, and Environmental Engineering, University of Saskatchewan, Saskatoon, SK, Canada

10 Correspondence to: Sepidehalsadat. Hendi (shendi@eoas.ubc.ca), Mostafa Gorjian (mgorjian@eoas.ubc.ca)

\begin{abstract}
Fiber optic sensing technology has recently become popular for oil and gas, mining, geotechnical engineering, and hydrogeology applications. With a successful track record in many applications, distributed acoustic sensing using straight fiber optic cables has become a method of choice for seismic studies. However, distributed acoustic sensing using straight fiber optic cables is not able to detect off-axial strain, hence a helically wound cable design was introduced to overcome this limitation. The helically wound cable field data in New Afton deposit showed that the quality of the data is tightly dependent on the incident angle (the angle between the ray and normal vector of the surface) and surrounding media.

We introduce a new analytical two-dimensional approach to determine the dynamic strain of a helically wound cable in terms of incident angle in response to elastic plane waves propagating through multilayered media. The method can be used to quickly and efficiently assess the effects of various materials surrounding a helically wound cable. Results from the proposed analytical model are compared with results from numerical modeling obtained with COMSOL Multiphysics, for scenarios corresponding to a real installation of helically wound cable deployed underground at the New Afton mine in British Columbia, Canada. Results from the analytical model are consistent with numerical modeling results.

Our modeling results demonstrate the effects of cement quality, and casing installment on the quality of the helically-wound cable response. Numerical modeling results and field data suggest that, even if reasonably effective coupling achieved, the soft nature of the rocks in these intervals would result in low fiber strains for the HWC. The proposed numerical modeling workflow would be applied for more complicated scenarios (e.g., non-linear material constitutive behaviour, and the effects of pore fluids). The results of this paper can be used as a guideline for analyzing the effect of surrounding media and incident angle on the response of helically wound cable, optimizing the installation of helically wound cable in various conditions, and to validate boundary conditions of 3-D numerical model built for analyzing complex scenarios.
\end{abstract}


https://doi.org/10.5194/se-2020-197

Preprint. Discussion started: 7 December 2020

(c) Author(s) 2020. CC BY 4.0 License.

\section{(c) (1)}

\section{Introduction}

A Cutting-edge fiber-optic technology has recently become popular in geophysical, mining, geotechnical, hydrological, environmental, and oil and gas applications. Fiber optic sensing offers many advantages over conventional sensors including lower price, lower weight, large-area coverage when compared to point sensors, simultaneous sensing over the entire length of the fiber optic cable, low sensitivity of glass fiber to electromagnetic radiation, and the possibility of use in harsh environments (Madjdabadi, 2016). A comprehensive literature review about the different types of fiber optic sensing technology, in terms of application, modulation and scattering of light, and polarization can be found in Madjdabadi (2016), Miah and Potter (2017), and Hartog (2018). In earth-related engineering, three main fiber optic sensing categories are commonly used: distributed temperature sensing (DTS), distributed strain sensing (DSS), and distributed acoustic sensing (DAS) (Ranjan and McColpin, 2013; Daley et al., 2013; Hornman, 2015).

Distributed Acoustic Sensing is commonly applied to measure acoustic signals in seismic applications. In this case, fiber optic cables replace conventional point sensors such as geophones and accelerometers. DAS has been used in vertical seismic profile (VSP) surveys for over 12 years (Daley et al., 2013), and is often used to monitor micro-seismicity associated with hydraulic fracturing (Hornman, 2015). In terms of environmental application, DAS has been recently used in $\mathrm{CO}_{2}$ sequestration projects to characterize storage reservoirs and to map the progression of the $\mathrm{CO}_{2}$ plume within geological formations (Miller et al., 2016; Harris et al., 2016). In mining, DAS-VSP was used to image steeply-dipping ore at the Kylylahti Cu-Au-Zn deposit in Finland and to provide geological information at the New Afton $\mathrm{Cu}-\mathrm{Au}$ deposit in Canada (Riedel et al., 2018; Bellefleur et al., 2020).

50 To date, most DAS applications use cables with straight optical fibers deployed in trenches at surface or in boreholes. Fiber optic cables are most sensitive to seismic waves exerting strain in the axial direction (i.e., longitudinal to the fiber). Thus, straight fiber optic cables are only suitable for certain survey geometries (Figure 1). These include VSP applications, because the reflected compressional seismic waves propagate predominantly in a direction parallel to the fiber axis, and hydraulic fracturing monitoring, because the monitoring wells are proximal to the induced microseismic events hence the waveforms reaching the monitoring well possess sufficient curvature to generated a detectable component in the direction of the fiber axis. Conversely, DAS cannot detect seismic strain for hydraulic fracturing monitoring using vertical wells and surface seismic measurement due to a lack of resultant axial dynamic strain along the fiber optic cable (Hornman, 2015).

The broadside sensitivity of DAS can be improved by using helically wound fiber optic cable (HWC) (Den Boer, 2017). HWC consists of fibers wrapped around a mandrel core with a predetermined wrapping angle ( $\alpha$ ) (Figure 2). The wrapping angle controls the sensitivity of the cable, with lower wrapping angles providing higher sensitivity to broadside seismic waves. Other factors which affect HWC performance are the properties of the engineered media surrounding the cable and the coupling of these media with the rock formation (Kuvshinov, 2016). At the New Afton $\mathrm{Cu}$-Au deposit in Canada, poor coupling and soft formations in the immediate vicinity of the monitoring borehole caused weak seismic amplitudes in data acquired with HWC, but had minimal effects on data measured on a coincident straight fiber optic cable (Bellefleur et al., 2020). This experience 
https://doi.org/10.5194/se-2020-197

Preprint. Discussion started: 7 December 2020

(c) Author(s) 2020. CC BY 4.0 License.

(c) (i)

65 illustrates the importance of understanding the effect of surrounding media on HWC in the selection and design of DAS monitoring systems.

The main objectives of this work were to help address the following questions:

- Why does HWC sometimes acquire low-quality data in the field?

- What are the effects of the surrounding media and incident angle on their impacts on cable design and installation techniques?

In order to meet these objectives, we first developed a 2-D analytical solution to model HWC's dynamic strain due to acoustic waves. The analytical solution provides a means of estimating HWC response using a relatively simple model that does not require specialized software. In the context of this work, the greatest value of this analytical solution was the fact that it provided a means to verify a 2-D numerical model that was developed using the commercial software COMSOL Multiphysics. Then, having established the effectiveness of the 2-D numerical model, a 3-D model was developed using the same methods and tools. Material properties and HWC geometry used for the modeling were based on the field conditions and data previously acquired during a survey at the New Afton $\mathrm{Cu}$-Au deposit in Canada. The HWC fiber optic cable's output for different possible field installation scenarios was compared to provide insight toward optimizing field deployments. Service companies could benefit by using this workflow prior to installation of HWC fiber optic cable in the field.

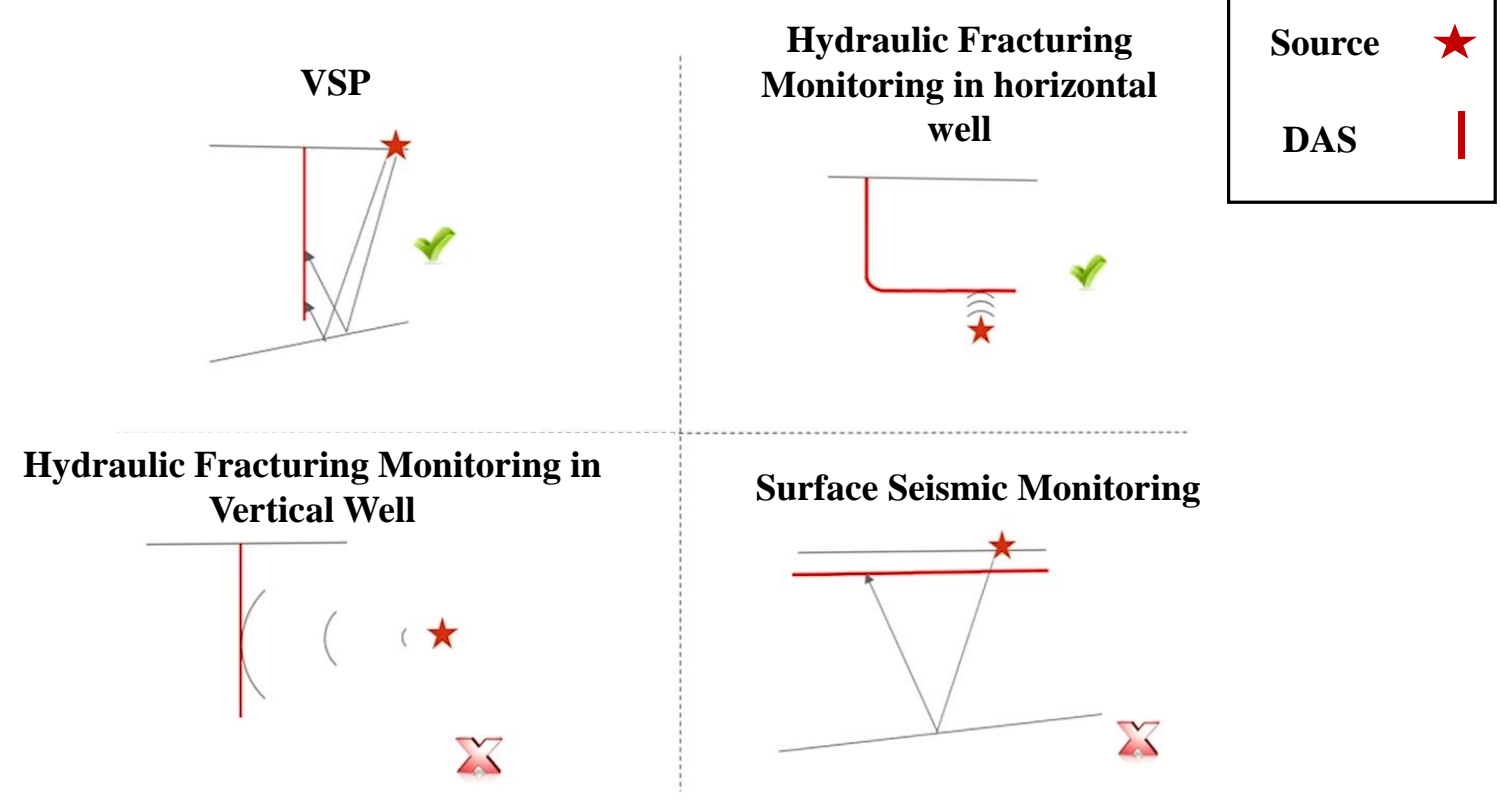

Figure 1: Scenarios in which DAS monitoring can be effective for detecting dynamic strains include VSP's and hydraulic fracturing monitoring using horizontal wells, due to sufficient strain occurring parallel to the fiver axis. Scenarios in which DAS is less effective include hydraulic fracturing monitoring using vertical wells and surface seismic monitoring due to limitations in detecting off-axial dynamic strain (Hornman, 2015). 
a)
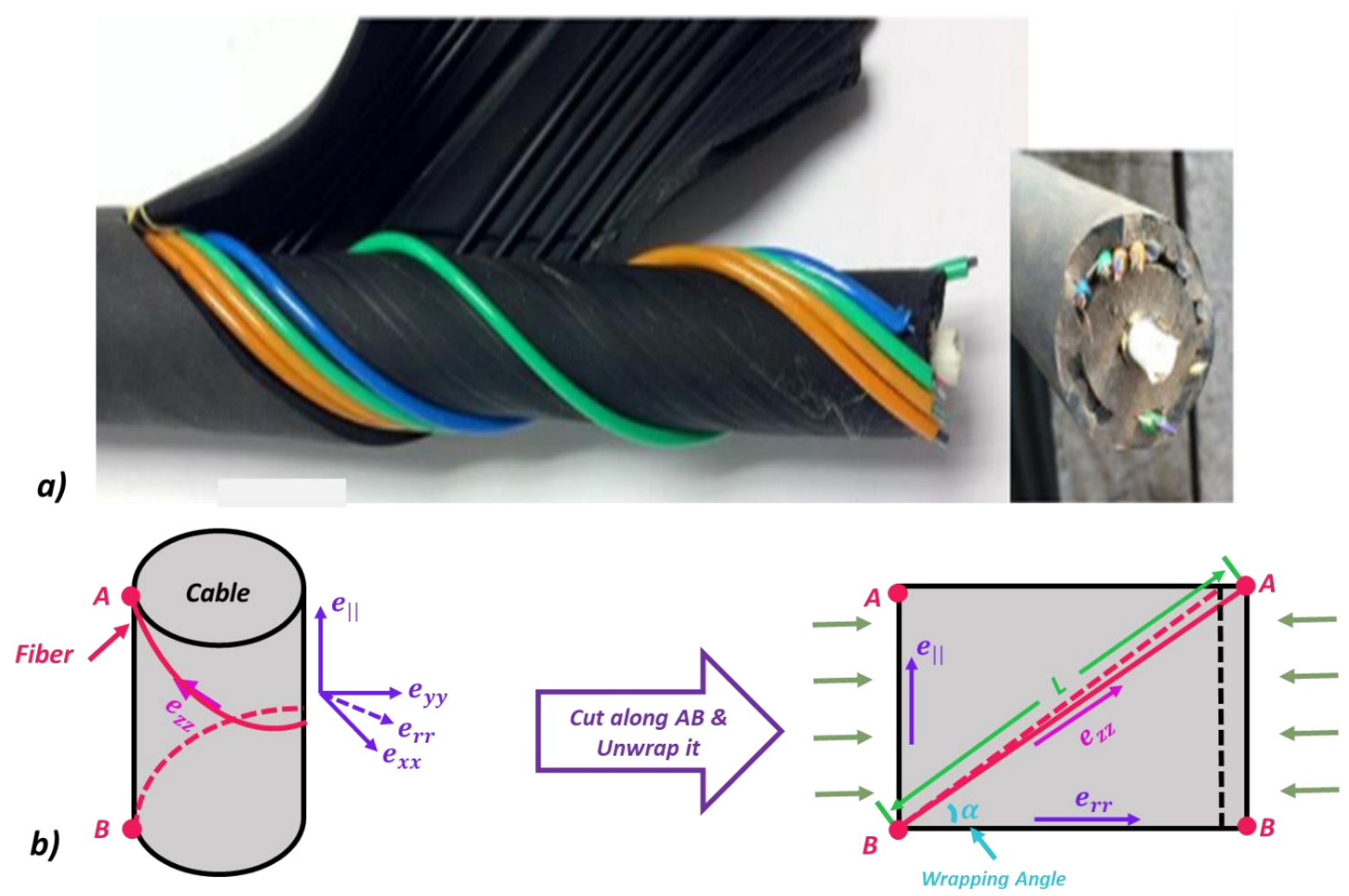

Figure 2: (a) Photograph of HWC used in a trench project (from Daley et al., 2016), (b) Illustration showing the meaning of wrapping angle $(\alpha)$. If the cylindrical surface of a cable (grey) is cut along $A B$, and unwrapped to a horizontal plane, the fiber trajectory would be represented by the diagonal red line shown in the image on the right. The wrapping angle $(\alpha)$ is the angle between the fiber and the circumference of the cable (BB). When a wave hits the HWC, the cable is deformed (dashed black line), and accordingly the fiber is deformed (red dashed line). Dynamic strains (denoted by $e$ ) imposed on a HWC due to acoustic waves are defined in an $x$, y, || coordinate system. (After Hornman, 2015)

\section{Methodology}

\subsection{D Analytical Modeling}

As presented in detail in Appendix A, the wave equation was solved to determine dynamic strain as a function of incident angle generated by dynamic stresses imposed by plane seismic waves propagating through a multilayered medium. Plane waves were assumed in order to represent a point source located in the far field. Longitudinal-wave properties of the materials were included in the derivation. Equations derived for this model are presented in Appendix A in a form which facilitates comparison with the two-dimensional numerical simulation described later, specifically to confirm the boundary conditions and assumptions applied in simulation. 
https://doi.org/10.5194/se-2020-197

Preprint. Discussion started: 7 December 2020

(c) Author(s) 2020. CC BY 4.0 License.

(c) (i)

\section{$105 \quad 2.2$ Numerical Model}

The numerical models for this work were generated using the finite element COMSOL Multiphysics software to predict the axial strain of fiber as a response of incident angle of a compressional wave. The models were developed in the frequency domain, using a dominant frequency of $100 \mathrm{~Hz}$ in order to match the field conditions at a site of interest (New Afton mine; see below). Six scenarios with different combinations of mechanical properties for the materials within and around the borehole.

110 These scenarios were chosen to enable assessment of the effects of various potential geometries, material and conditions on DAS data measured with a HWC. For example, scenarios \#1 and \#2 compare the effect of soft and hard cement located between the casing and rock formation whereas scenarios \#3 and \#4 compare the effect of soft versus hard formations. Scenarios 5 and 6 investigate the effect of water located either inside or outside the casing. For this work, the geometries (Table 1) and properties (Table 2) of the materials were chosen to be similar to those of a DAS field experiment conducted at the New Afton

115 mine, Canada (Bellefleur et al., 2020). The rock properties were based on unpublished triaxial compression testing results obtained for representative samples of crystalline fragmental volcanic host rocks at the New Afton deposit. Samples were retrieved at depths ranging from 2 to $214 \mathrm{~m}$. The average values of elastic properties are presented in Table 2. The material properties related to the cable, casing and hard cement were taken from Kuvshinov (2015).

The six scenarios modeled are as follows:

- Scenario \#1: this scenario is composed of 5 layers (denoted by domains). In order of proximity to the center of the cable (i.e. fiber), they are: cable, hard cement, casing, hard cement and hard formation (Fig. 3).

- Scenario \#2: this scenario is composed of 5 layers. In order of proximity to the center of the cable, they are: cable, hard cement, casing, soft cement and hard formation (Fig. 3).

- Scenario \#3: this scenario is composed of 4 layers. In order of proximity to the center of cable, they are: cable, hard cement, casing and hard formation (Fig. 4).

- Scenario \#4: this scenario is composed of 4 layers. In order of proximity to the center of the cable, they are: cable, hard cement, casing and soft formation (soft cement) (Fig. 4).

- Scenario \#5: this scenario is made up 5 layers: In order of proximity to the center of the cable, they are cable, hard cement, casing, water and hard formation (Fig. 5).

130 - Scenario \#6: this scenario is made up 5 layers: In order of proximity to the center of the cable, they are cable, water, casing, hard cement, and hard formation (Fig. 6). 
. Table 1. Geometrical parameters used in numerical modeling.

\begin{tabular}{|l|l|l|}
\hline \multirow{2}{*}{ Material } & Geometrical parameter & Value \\
\hline \multirow{2}{*}{$\begin{array}{l}\text { Cement/water } \\
\text { (around the Cable) }\end{array}$} & Cable Diameter & $25.0 \mathrm{~mm}$ \\
\cline { 2 - 3 } & Cable Height & $\mathbf{\eta} / 12^{1}$ \\
\hline \multirow{2}{*}{ Casing } & Cement Diameter & $77.8 \mathrm{~mm}$ \\
\cline { 2 - 3 } & Cement Height & $\mathbf{\eta} / 12$ \\
\hline \multirow{2}{*}{$\begin{array}{l}\text { Cement/water } \\
\text { (around the Casing) }\end{array}$} & Casing Diameter & $88.9 \mathrm{~mm}$ \\
\cline { 2 - 3 } & Casing Height & $\mathbf{\eta} / 12$ \\
\hline \multirow{2}{*}{ Formation } & Cement Diameter & $96.0 \mathrm{~mm}$ \\
\cline { 2 - 3 } & Cement Height & $\mathbf{\eta} / 12$ \\
\hline
\end{tabular}

140 Table 2. Layer (domain) properties used for modeling

\begin{tabular}{|c|c|c|c|c|}
\hline Material & $\begin{array}{c}\rho \\
\left(\mathrm{kg} \mathrm{m}^{-3}\right)\end{array}$ & $\begin{array}{c}\text { Compressional } \\
\text { Velocity }\left(\mathrm{V}_{\mathrm{p}}\right) \\
\left(\mathrm{m} \mathrm{s}^{-1}\right)\end{array}$ & $\begin{array}{c}\mathrm{E}^{\prime 2} \\
(\mathrm{GPa})\end{array}$ & $\vartheta$ \\
\hline Hard Formation & 2734 & 5736 & 60.1 & 0.28 \\
\hline Cable & 1200 & 1183 & 1.6 & 0.15 \\
\hline Casing & 8050 & 5635 & 200.0 & 0.28 \\
\hline Hard Cement & 2240 & 2728 & 15.0 & 0.20 \\
\hline Water & 1000 & 1500 & N/A & N/A \\
\hline $\begin{array}{c}\text { Soft Cement/Soft } \\
\text { Formation }\end{array}$ & 1440 & 1963 & 5.0 & 0.20 \\
\hline
\end{tabular}

\footnotetext{
${ }^{1} \boldsymbol{\eta}={ }^{(\text {Formation Compressional Velocity) } /(\text { Dominant Frequency) }}$

${ }^{2} \mathrm{E}$ ' is plane strain Young's modulus which is equivalent to $\mathrm{E} /\left(1-v^{2}\right)$
} 
https://doi.org/10.5194/se-2020-197

Preprint. Discussion started: 7 December 2020

(c) Author(s) 2020. CC BY 4.0 License.

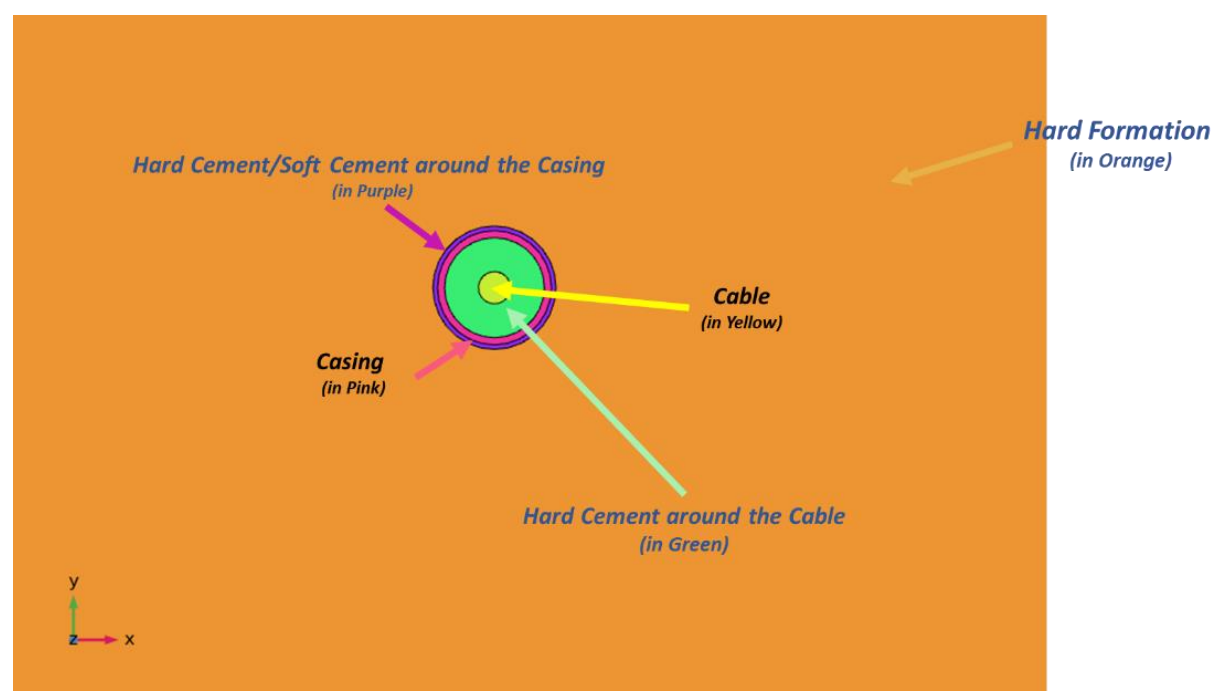

145 Fig. 3. Geometry for Scenario \#1 and \#2.

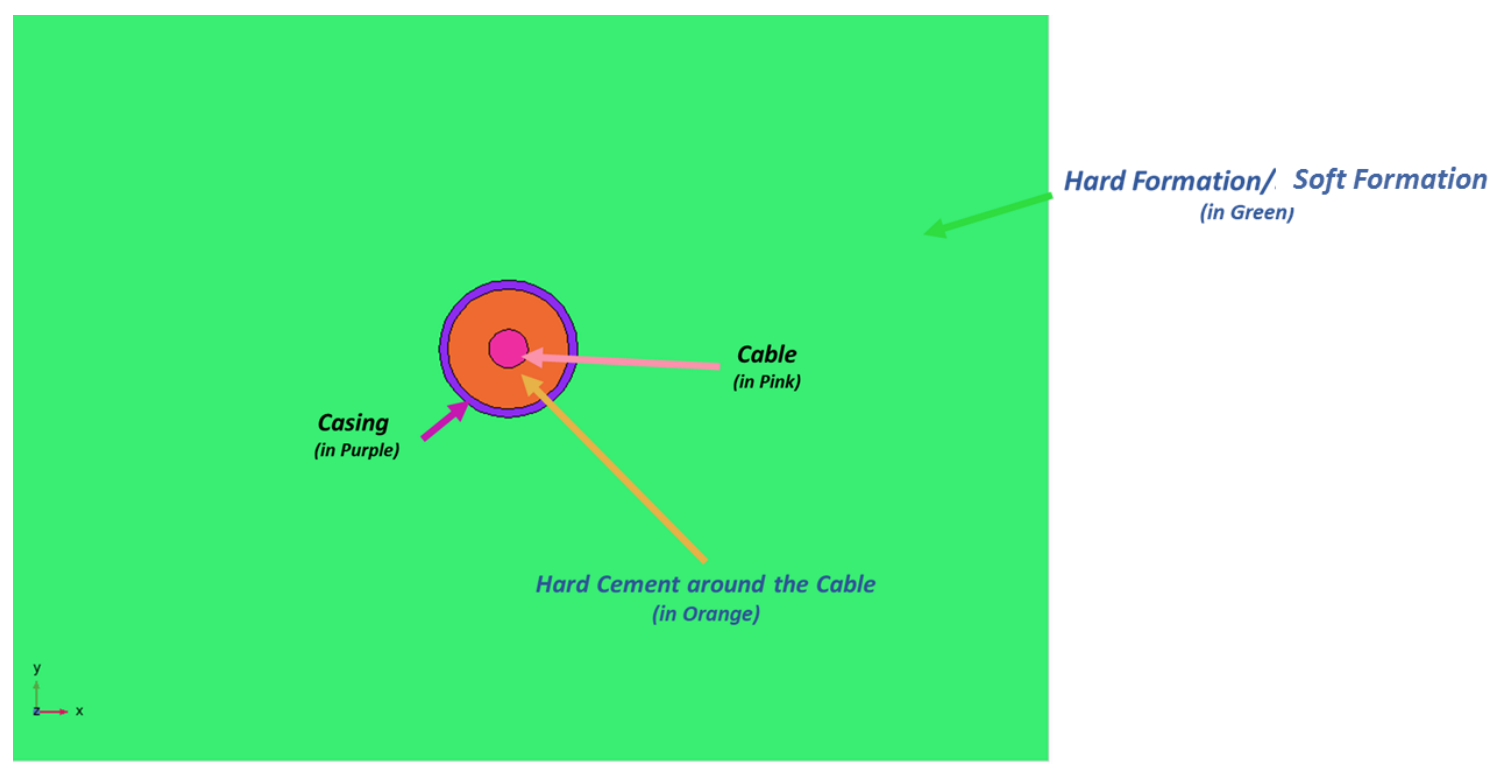

Figure 4. Geometry for scenario \#3 and \#4 


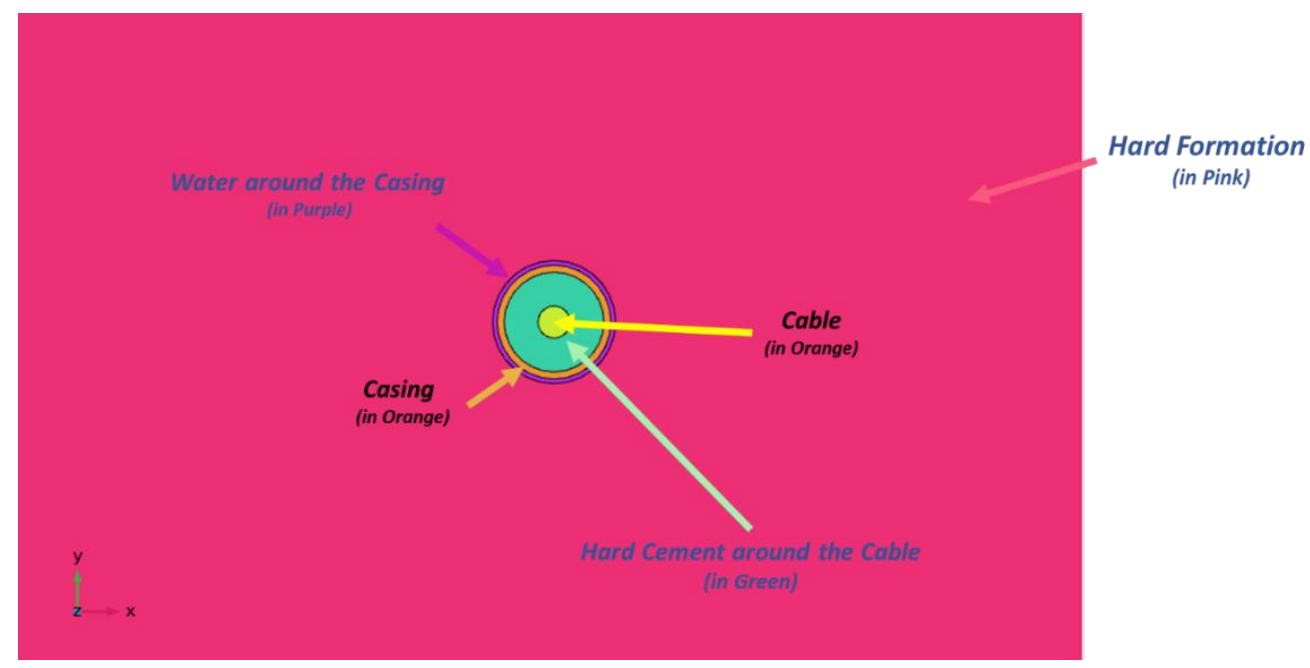

Figure 5. Geometry for scenario \#5

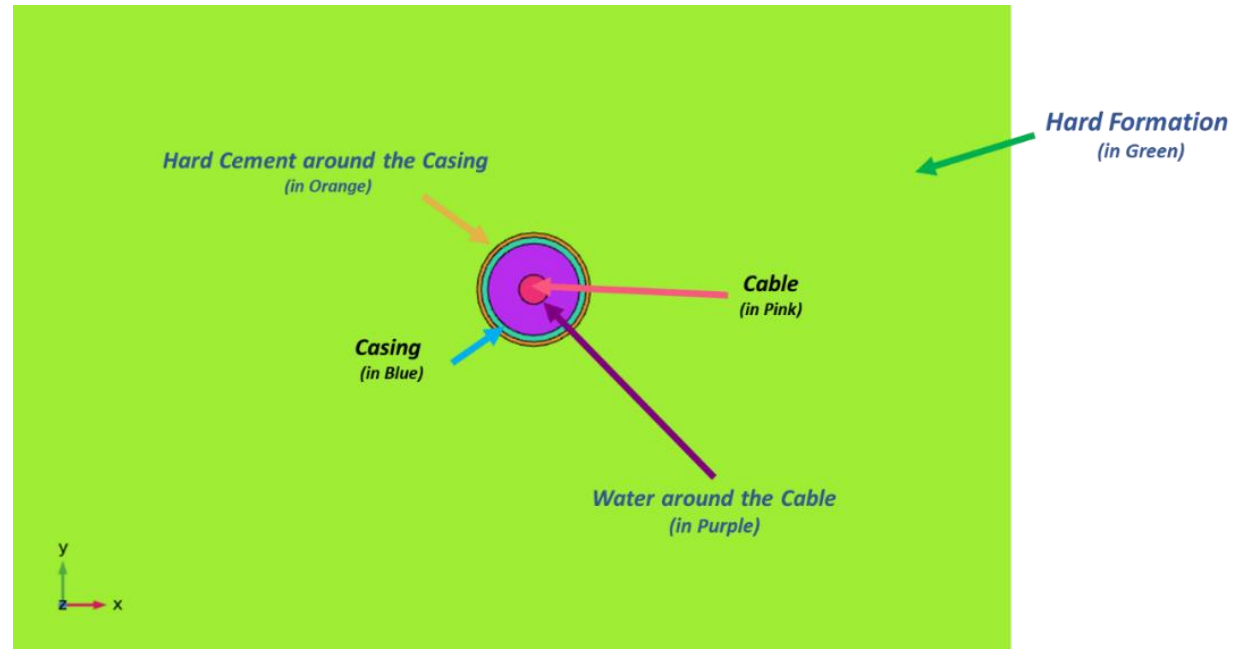

Figure 6. Geometry for scenario \#6

In all scenarios, strain was simulated for a helically wound cable with a wrapping angle $(\alpha)$ of $30^{\circ}$ (Figure 2 ). As shown in Appendix A (equation A.47), the axial and radial strains of the cable were calculated separately and combined together with 155 the wrapping angle to calculate the axial strain of the fiber

\subsection{Boundary Condition for Numerical Modeling}

In The geometry and boundary conditions used for the 2-D numerical simulations are shown in Figure 7. This model treats the material domains around the borehole as planar, rather than concentric. The prescribed displacement boundary condition was 
https://doi.org/10.5194/se-2020-197

Preprint. Discussion started: 7 December 2020

(c) Author(s) 2020. CC BY 4.0 License.

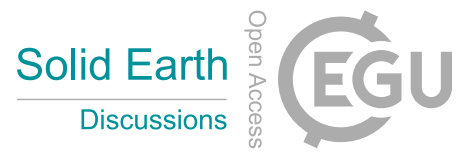

(c) (1)

160 selected for the right edge of the model in order to model arrival of the incoming wave on this surface (i.e., by prescribing dynamic strains representing a wave). A low reflecting boundary was selected on the left because it is assumed there is no reflection from infinity domain. Periodic boundaries were chosen on top and bottom boundaries to make the solutions equal on both sides.

The geometry and boundary conditions used for the 3-D simulations are presented in Figure 8.
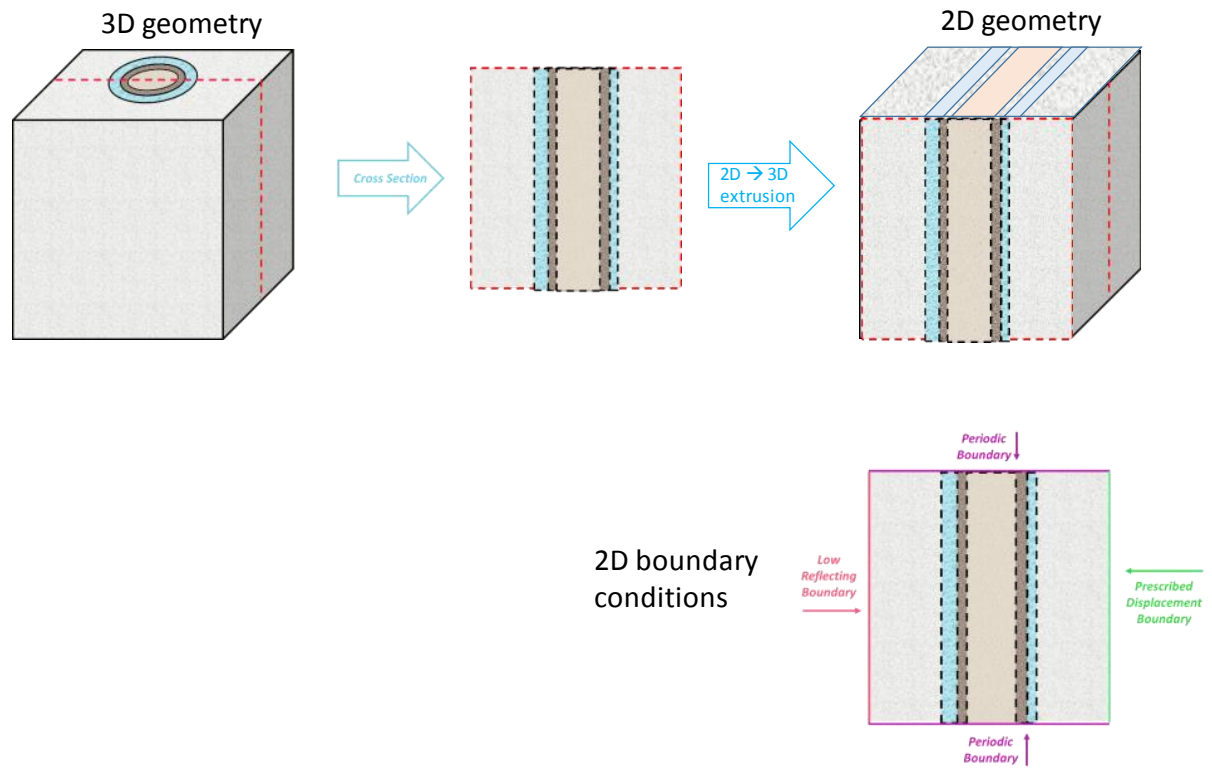

165 Figure 7. Illustration showing how a cross-section of the actual 3-D geometry was used to create a plane-strain, 2-D numerical model, and the boundary conditions applied to this model. 


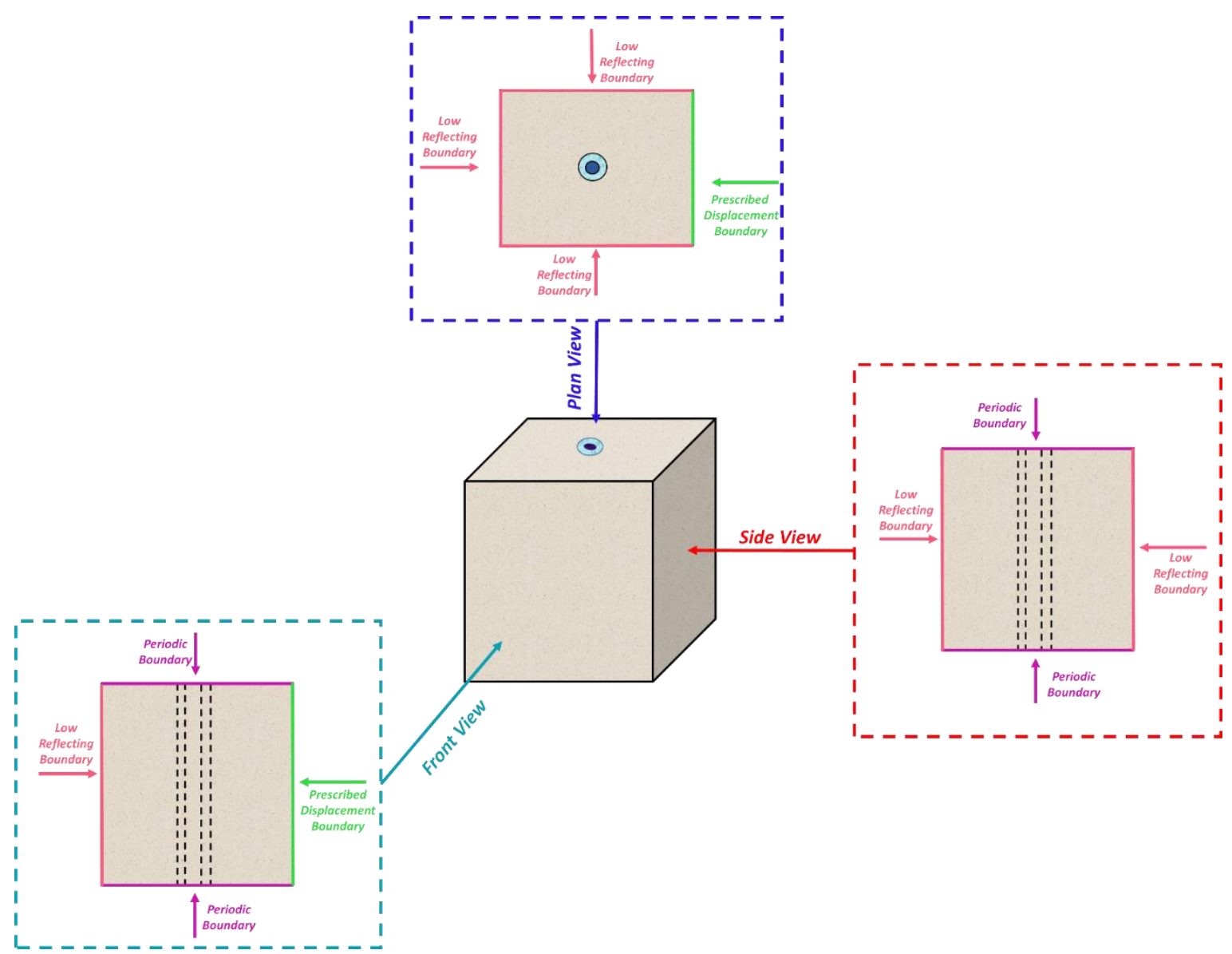

Figure 8. Assigned 2-D boundary conditions from 3-D model used in this simulation.

1703 Results

\subsection{Model Validation and 2D Sensitivity Analysis}

Scenarios 1 to 4 were modeled using both the 2D analytical and numerical models in order to: (i) validate the the numerical model, and (ii) to investigate the sensitivity of fiber response to cement stiffness and formation stiffness. The numerical and analytical results for scenarios \#1 to \#4 are presented in Figures 9 to 11. In all cases, the agreement between numerical and analytical results is good, with root mean square errors (calculated for the difference between the analytical and numerical solutions) in the 0.003 to 0.004 range. The effect of the stiffness of the cement between the rock formation and casing is shown in Figure 9. The analytical responses are almost identical for both scenarios whereas numerical responses differ slightly for low angles of incidence. At those angles $\left(0-35^{\circ}\right)$, fiber strain is less when hard cement surrounds the casing. The effect of the stiffness of cement around the casing becomes negligible for high angles of incidence. The effect of rock formation stiffness on fiber strain is particularly significant (Figure 10). The fiber strain is lower for a soft formation, modeled here using the properties of soft cement, than for a hard rock formation. This should result in a weaker seismic signal measured with DAS 
https://doi.org/10.5194/se-2020-197

Preprint. Discussion started: 7 December 2020

(c) Author(s) 2020. CC BY 4.0 License.

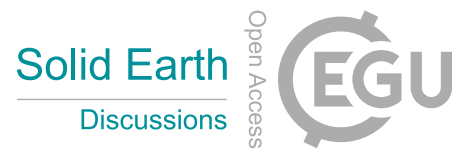

(c) (1)

for soft rock formations. Overall, responses from scenarios 1, 2, and 3 are similar, with only minor differences at low angles of incidence (Figure 11). Scenario 4 with soft rock formation properties displays the most impact on fiber strain.

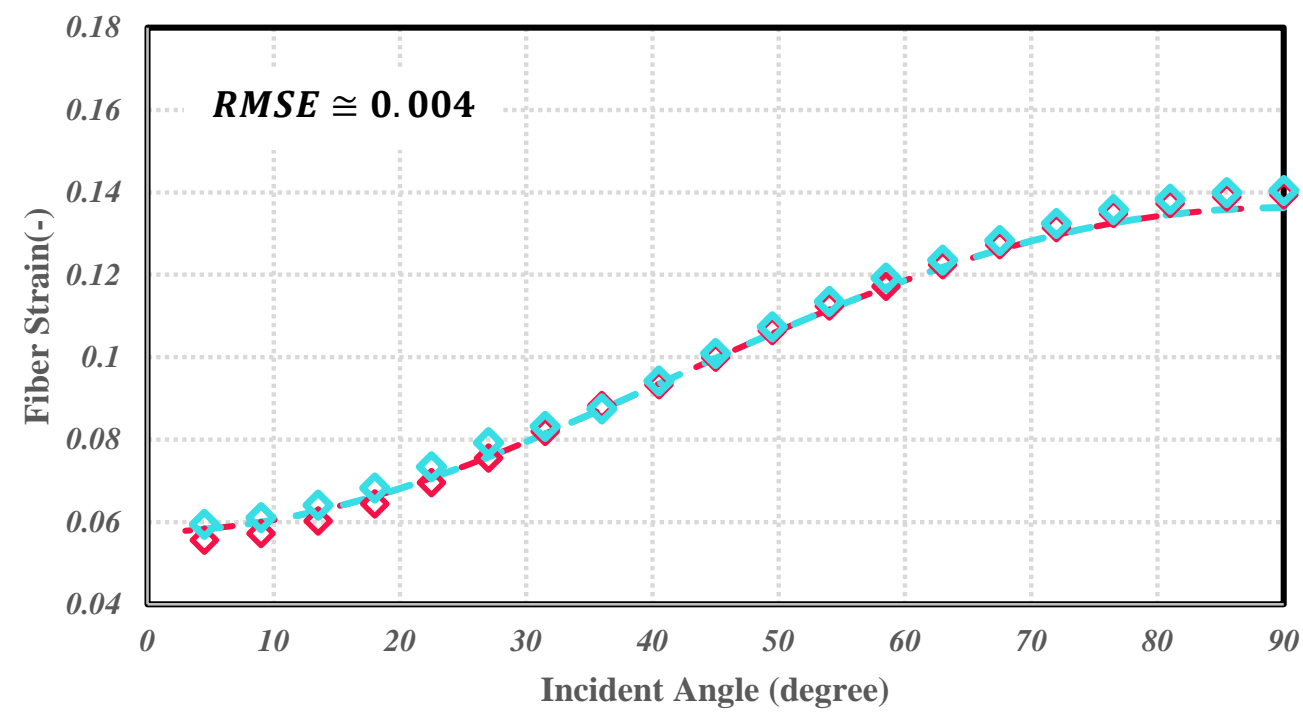

- - Scenario \#1 (Analytical Solution) - - Scenario \#2 (Analytical Solution)

- Scenario \#1 (Numerical Solution) • Scenario \#2 (Numerical Solution)

185 Figure 9. Axial strain for HWC fiber predicted using two-dimensional numerical model and analytical solution for scenarios \#1 and 2. RMSE denotes the root mean square error calculated for the difference between the analytical and numerical solutions. 
https://doi.org/10.5194/se-2020-197

Preprint. Discussion started: 7 December 2020

(c) Author(s) 2020. CC BY 4.0 License.
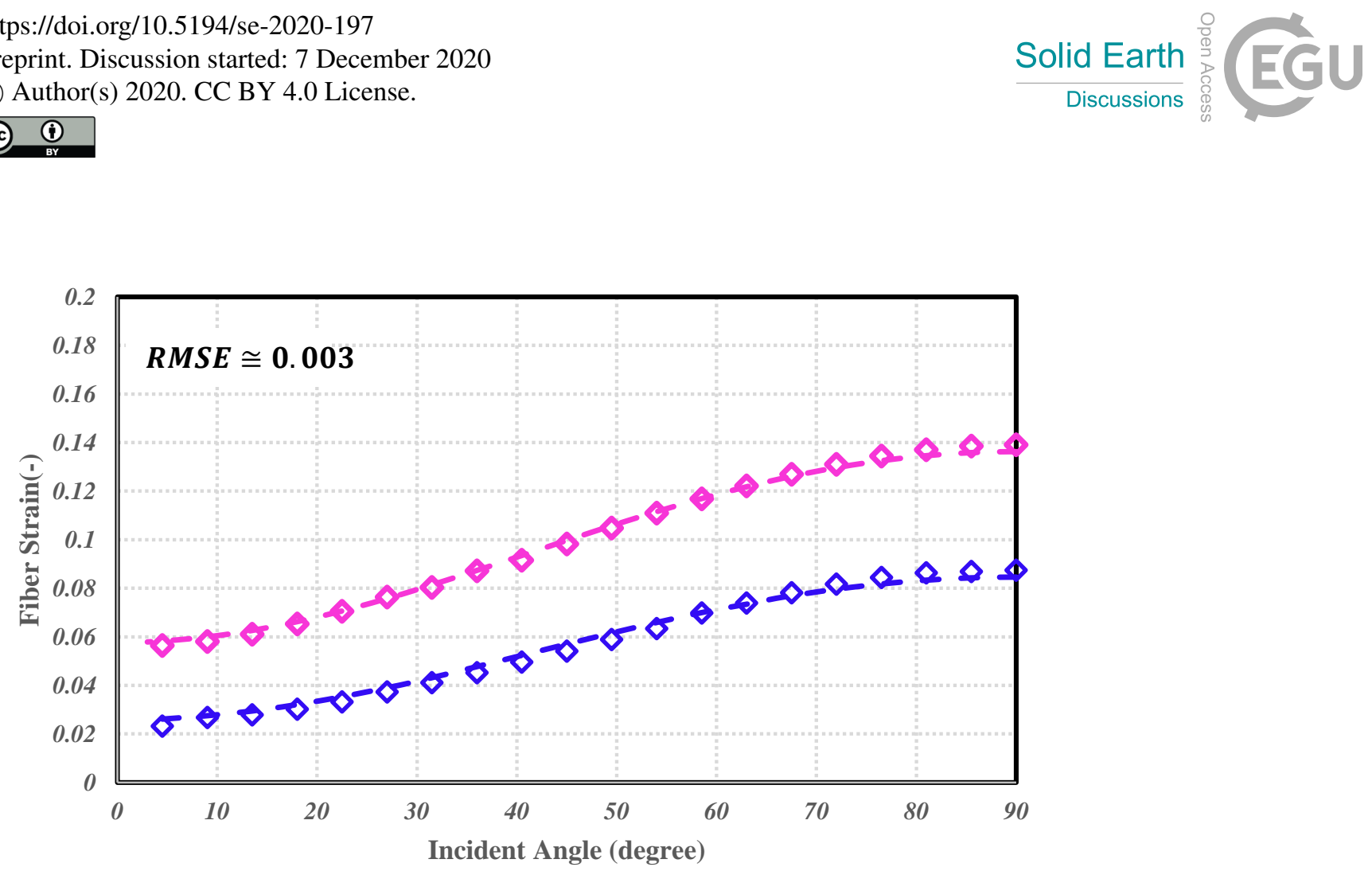

- Scenario \#3 (Analytical Solution) - - Scenario \#4 (Analytical Solution)

- Scenario \#3 (Numerical Solution) • Scenario \#4 (Numerical Solution)

190 Figure 10. Axial strain for HWC predicted using two-dimensional numerical model and analytical solution for scenarios \#3 and 4. RMSE denotes the root mean square error calculated for the difference between the analytical and numerical solutions. 


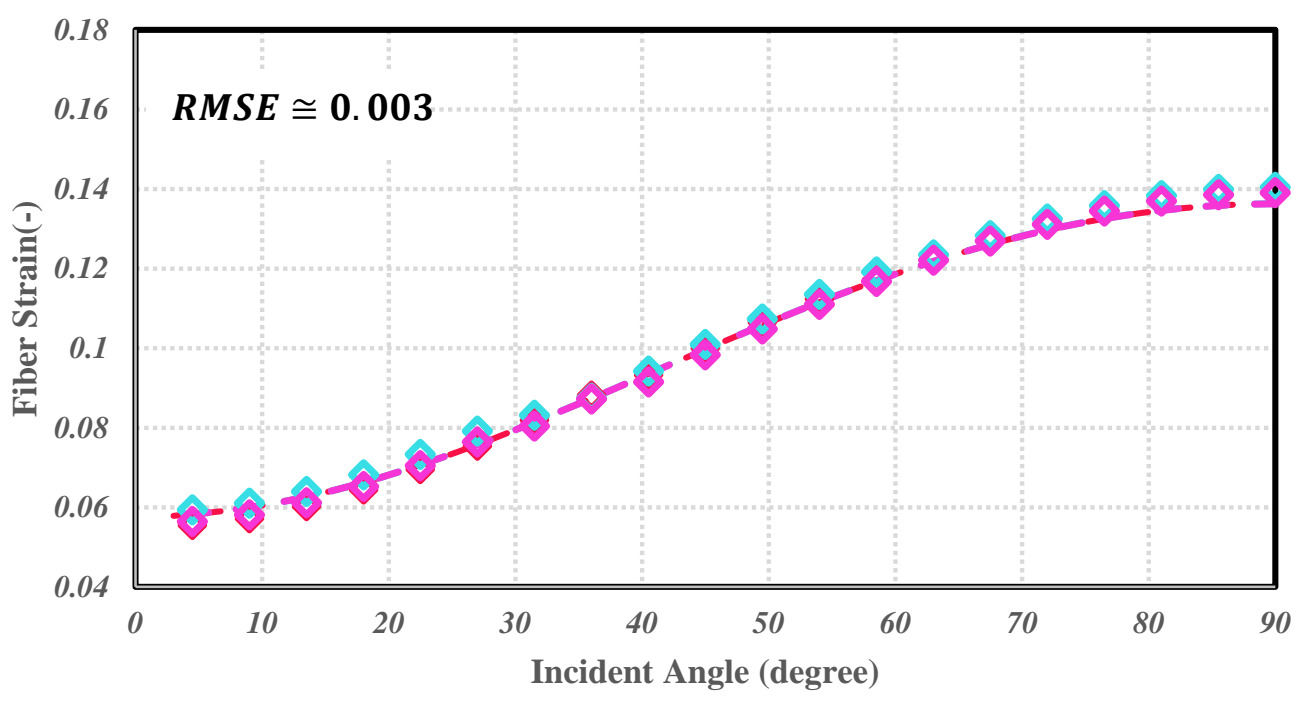

$$
\begin{aligned}
& \text { - - Scenario \#1 (Analytical Solution) - - Scenario \#2 (Analytical Solution) } \\
& \text { - Scenario \#3 (Analytical Solution) • Scenario \#1 (Numerical Solution) } \\
& \text { - Scenario \#2 (Numerical Solution) - Scenario \#3 (Numerical Solution) }
\end{aligned}
$$

Figure 11. Axial strain for HWC predicted using two-dimensional numerical model and analytical solution for scenarios \#1, 2, and

\subsection{D Numerical Modeling Results}

Radial strain distributions generated using the three-dimensional numerical model for scenarios 1 to 6 are shown in Figures 12-17.

Figure 18 shows a comparison of modeled fiber strains for scenarios \#1 and \#2. These are identical 5-layer scenarios, except

\#1 assumes hard cement in the casing-formation annulus, whereas \#2 assumes a soft cement in this annulus. The results are nearly identical for incident angles less than $30^{\circ}$. However, for greater incident angles, the scenario with soft cement in the annulus (i.e., scenario \#2) is slightly more sensitive (i.e., nearly $10 \%$ greater fiber strain). This is interpreted to be due to the lower Young's modulus for soft cement, resulting in the fiber experiencing greater strain in response to an imposed dynamic stress. It should be noted that the analytical results for scenarios \#1 and \#2 (shown in Figure 9), showed a lesser difference between cable strain at high incident angles. A possible reason for this is because in two-dimensional analytical analysis, strain in the Y-direction was considered to be zero under the plane strain assumption. In 3D, the cylindrical casing would have a slight dampening (shielding) effect on strains transmitted to the inner cement and fiber cable, but in 2D a planar "casing" would have no such dampening effect.

Figure 19 shows a comparison of modeled fiber strains for scenarios \#3 and \#4. Both of these are 4-layer scenarios which assume that casing is in direct contact with the formation; as such, there is no casing-formation annulus. The difference between these scenarios is the fact that \#3 assumes a hard formation, whereas \#4 assumes a soft formation. The results are nearly 
https://doi.org/10.5194/se-2020-197

Preprint. Discussion started: 7 December 2020

(c) Author(s) 2020. CC BY 4.0 License.

(c) (i)

identical for incident angles less than $5^{\circ}$, but with increasing angle scenario \#3 shows a much stronger response (strains at $90^{\circ}$ angle nearly five times greater to \#3 versus \#4). For the same frequency, the wave number of the hard formation is more than that of the soft formation. As a result, seismic energy attenuation is higher in the soft formation than in the hard formation.

215 Accordingly, less seismic energy is transmitted to the cable in scenario \#4, compared to scenario \#3, resulting is less strain for scenario \#4.

Figure 20 shows a comparison of modeled fiber strains for scenarios \#5 and \#6. These are both 5-layer scenarios similar to scenario \#1, except for one different in each case. In scenario \#5, it is assumed that the casing-formation annulus contains water rather than hard cement. In scenario \#6, it is assumed that the cable-casing annulus contains water rather than hard cement. Scenario \#6 shows a trend of decreasing strain with increasing incident angle, up to roughly $18^{\circ}$. Overall, the results show that the existence of water in the media surrounding the cable results in lower fiber strains than most of the other scenarios. More specifically, the maximum strain (which occurs at $90^{\circ}$ incident angle for all scenarios) is roughly 0.0065 for scenario \#5 and 0.0185 for scenario, compared to values in the 0.027 to 0.05 range for scenarios \#1 to \#3. (The only other scenario with a comparably low strain, at 0.009 , is scenario \#4 which, as discussed in the previous paragraph, assume a soft, highly-attenuating formation). The low strains observed for scenarios \#5 and \#6 are mainly due to the interfaces between solid and water forming a free surface, which acts to decompose incident waves into surface waves and compressional waves. Accordingly, less compressional energy is transmitted to the fiber cable. Though this is true of both scenarios \#5 and \#6, strains are greater in \#6 because cable extension/contraction is uninhibited when the cable is within water rather than cement.

Figure 21 shows a comparison of modeled fiber strains for scenarios \#1 and \#3. These are based on the same material properties, except scenario \#1 includes a cement-filled casing-formation annulus (5-layer system) whereas scenario \#3 assumes direct contact between the casing and formation (4-layer system). Both scenarios show relatively high fiber strains, with scenario \#3 having the greatest strains of all scenarios considered; and scenario \#1 having the third highest (only slightly less than scenario \#2). As such, the number of layers, as a stand-alone factor, should not be expected to result in poor signal quality for a HWC, assuming the layers present are hard (i.e., stiff) and well coupled. 


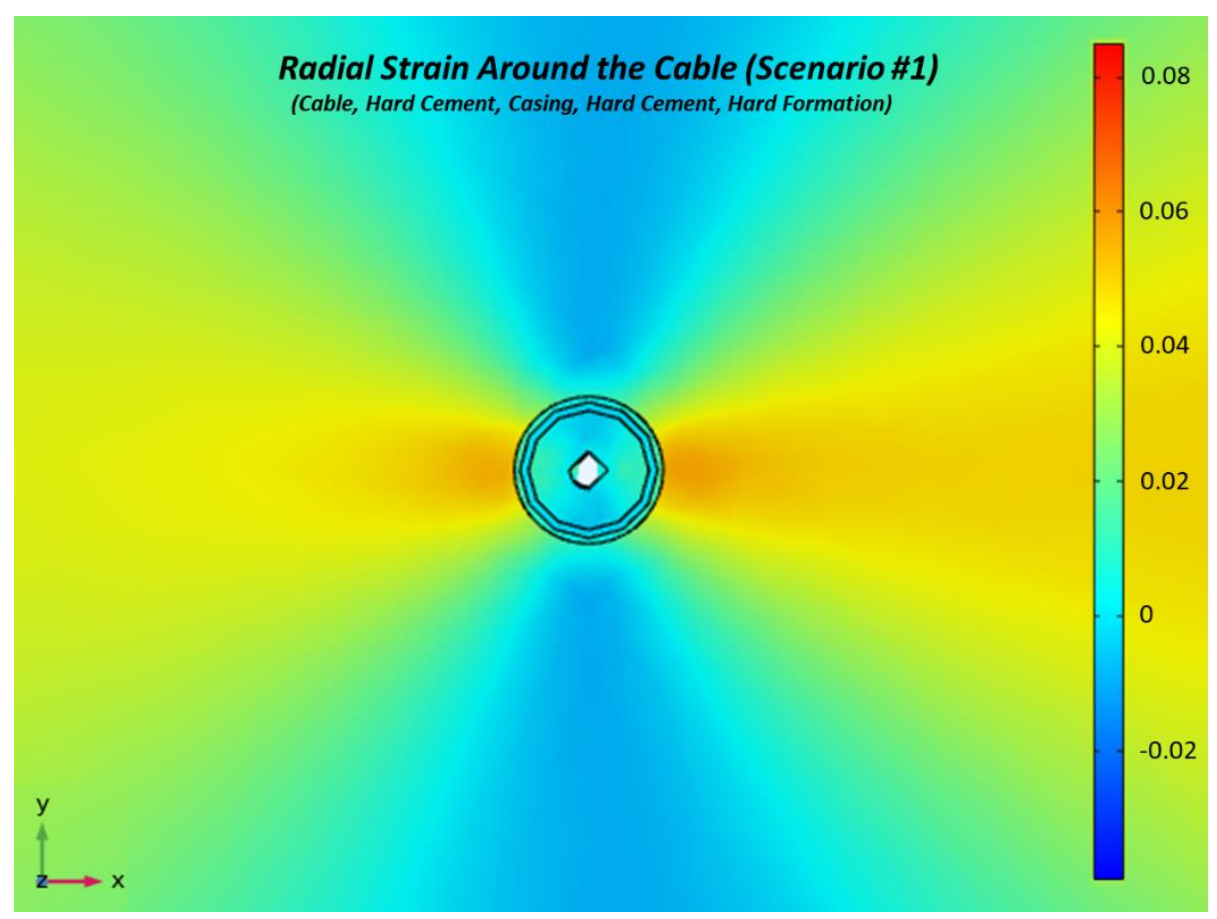

Figure 12. Radial strain around the Cable, Scenario \#1(Incident angle $=90^{\circ}$; i.e., incident waveform is incoming from the right).

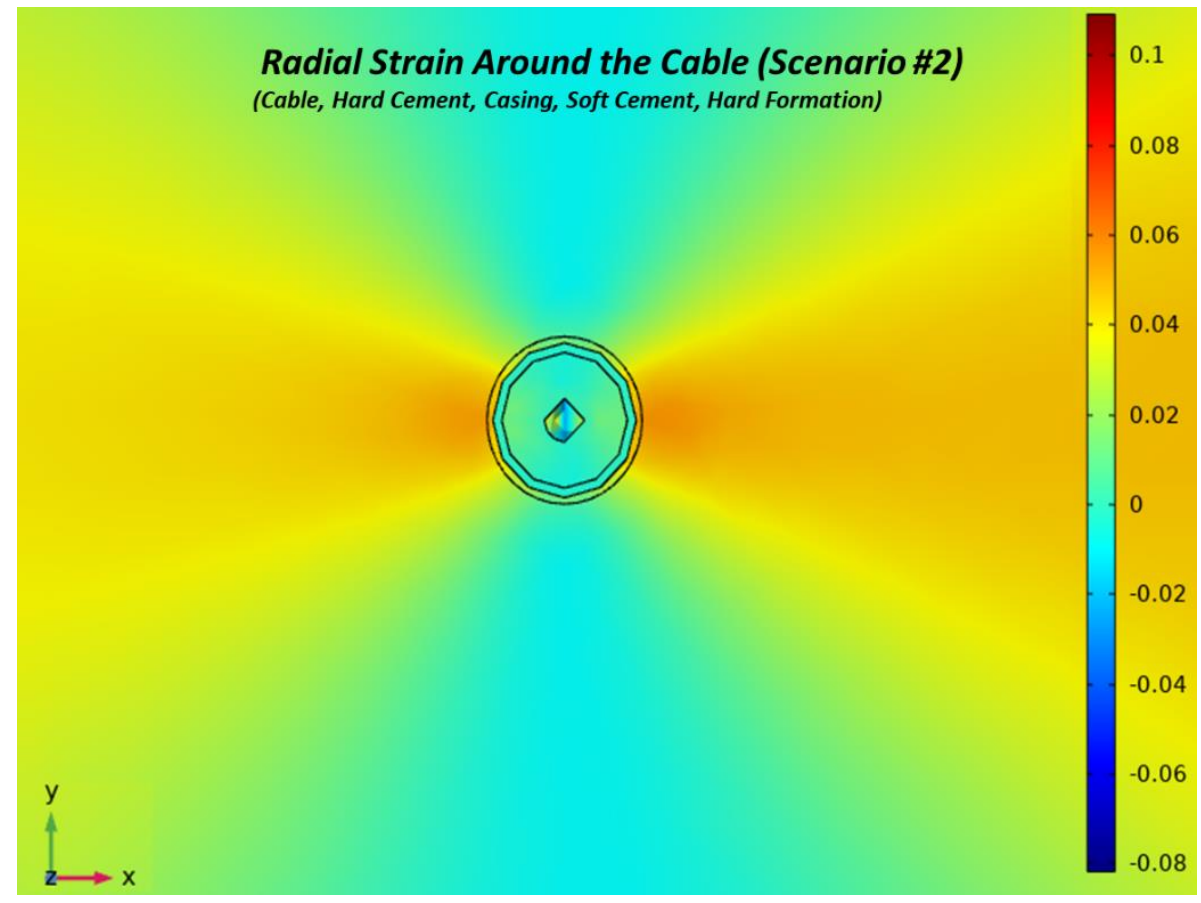

Figure 13. Radial strain around the Cable, Scenario \#2 $\left(\right.$ Incident angle $=90^{\circ}$ ). 


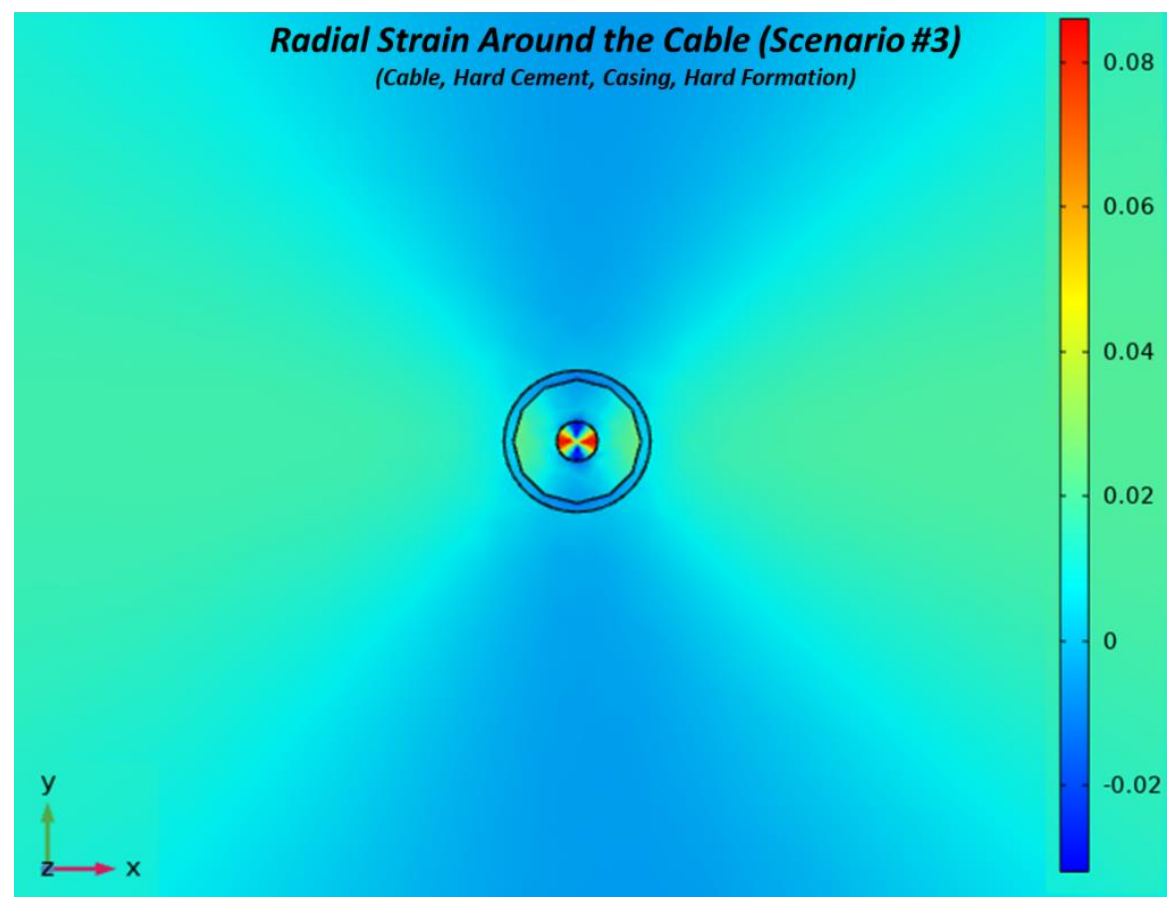

240 Figure 14. Radial strain around the Cable, Scenario \#3 (Incident angle $=90^{\circ}$ ).

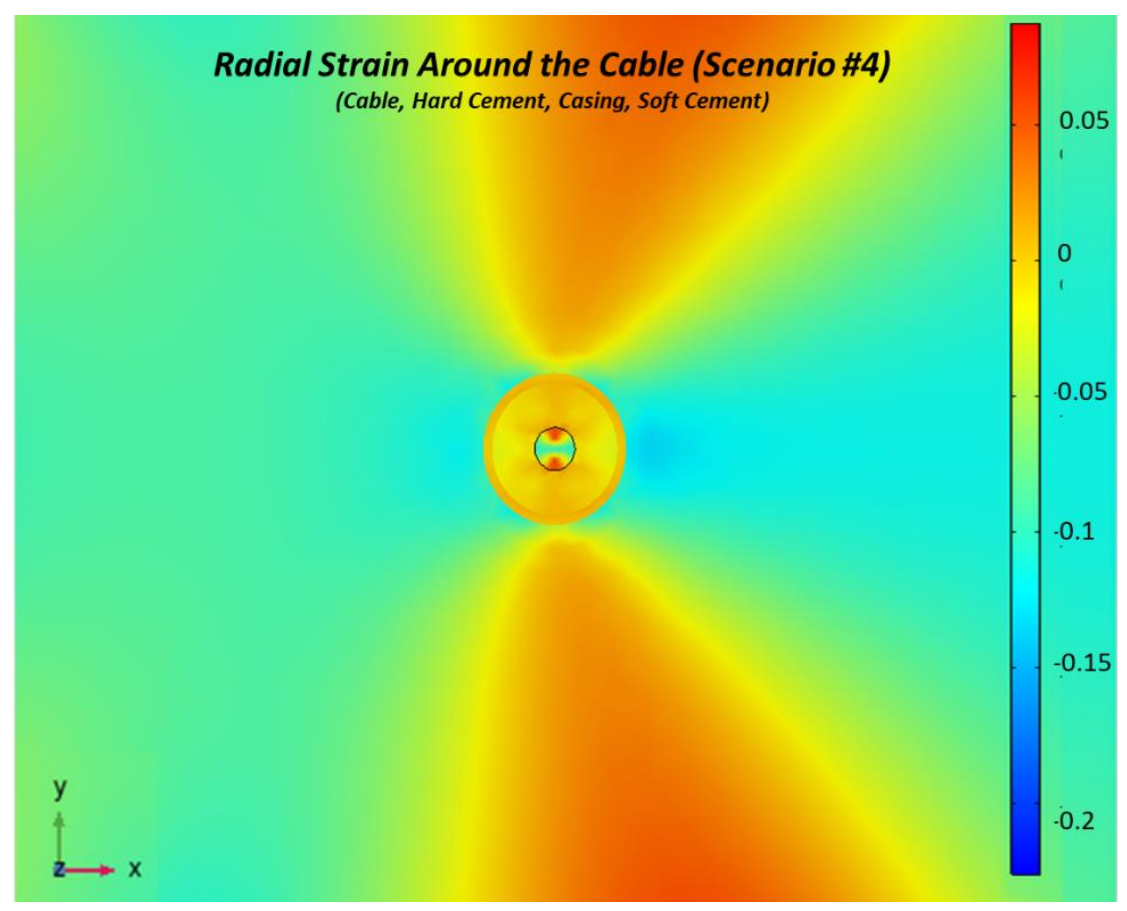

Figure 15. Radial strain around the Cable, Scenario \#4 (Incident angle $=90^{\circ}$ ). 


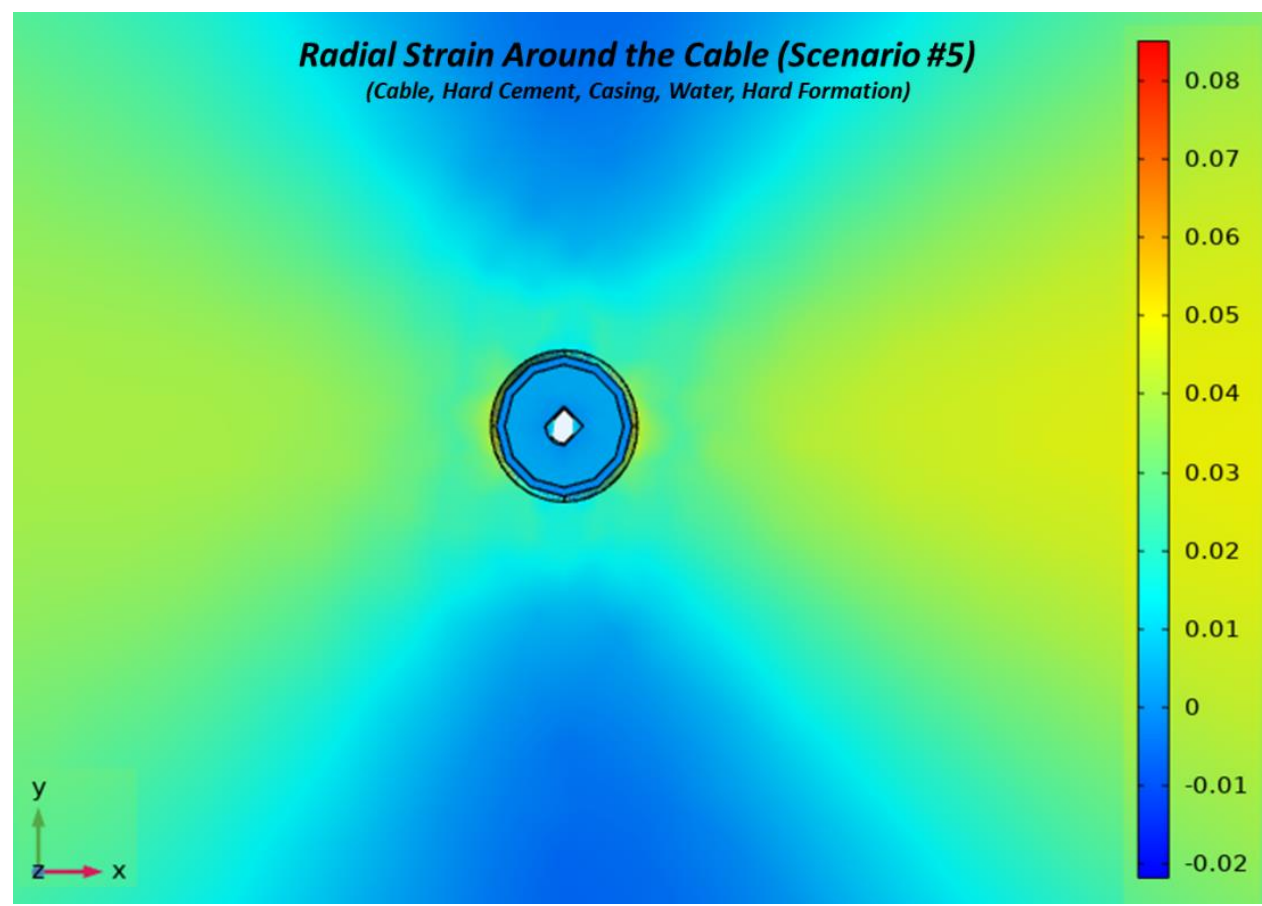

245 Figure 16. Radial strain around the Cable, Scenario \#5 (Incident angle $=90^{\circ}$ ).

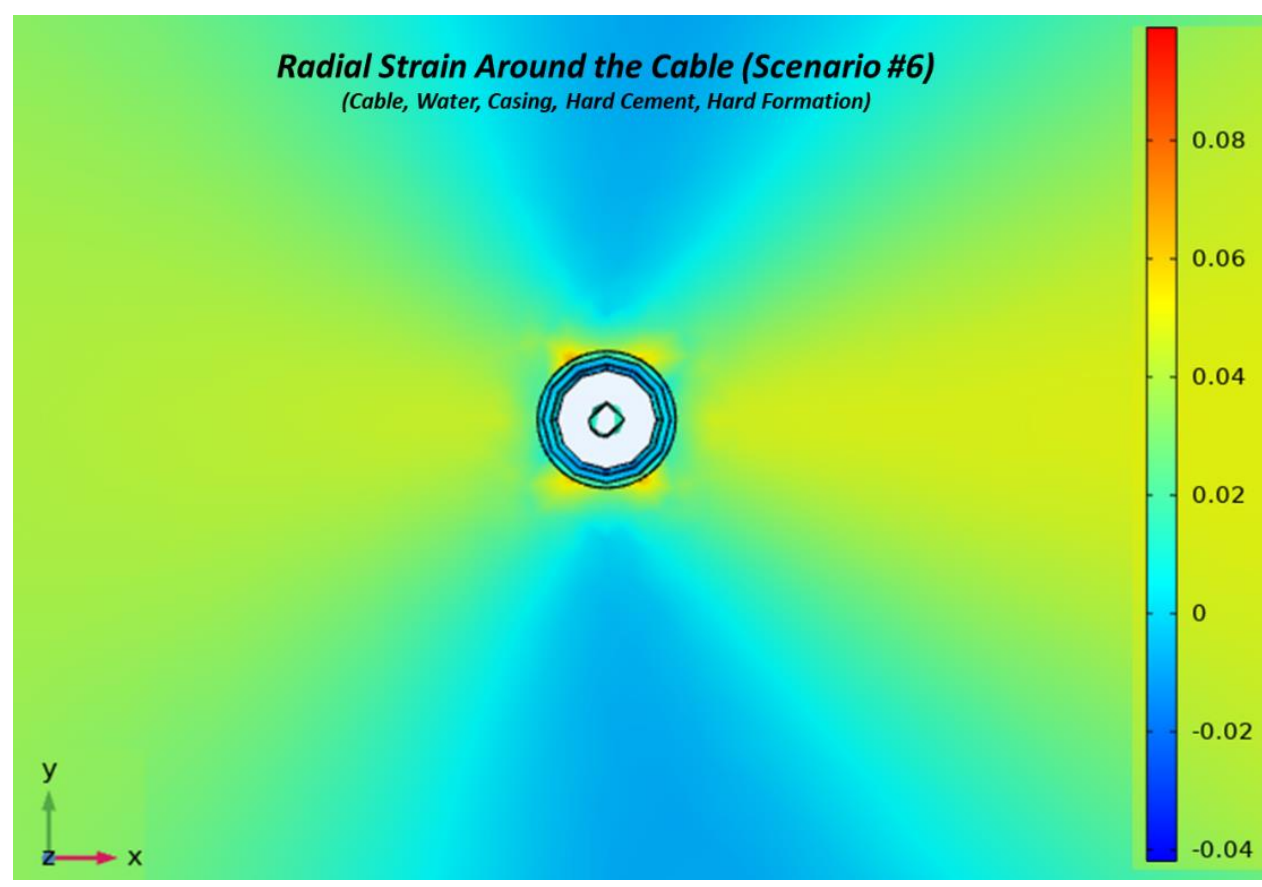

Figure 17. Radial strain around the Cable, Scenario \#6 (Incident angle $=90^{\circ}$ ). 
https://doi.org/10.5194/se-2020-197

Preprint. Discussion started: 7 December 2020

(c) Author(s) 2020. CC BY 4.0 License.

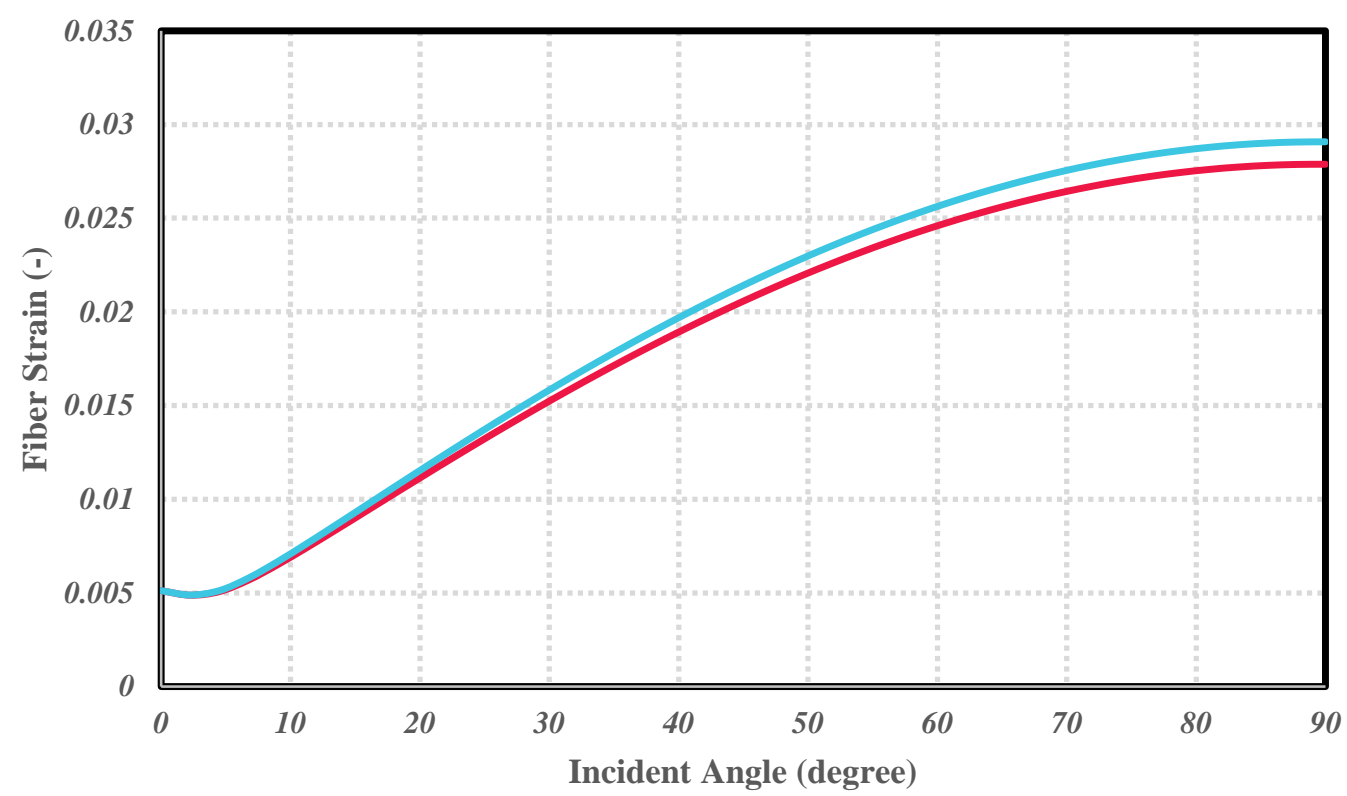

Scenario \#1 (Numerical Solution) $\quad$ Scenario \#2 (Numerical Solution)

Figure 18. Investigation the effect of cement quality surrounding the casing on the acoustic response of fiber (comparison between scenarios \#1 and \#2.

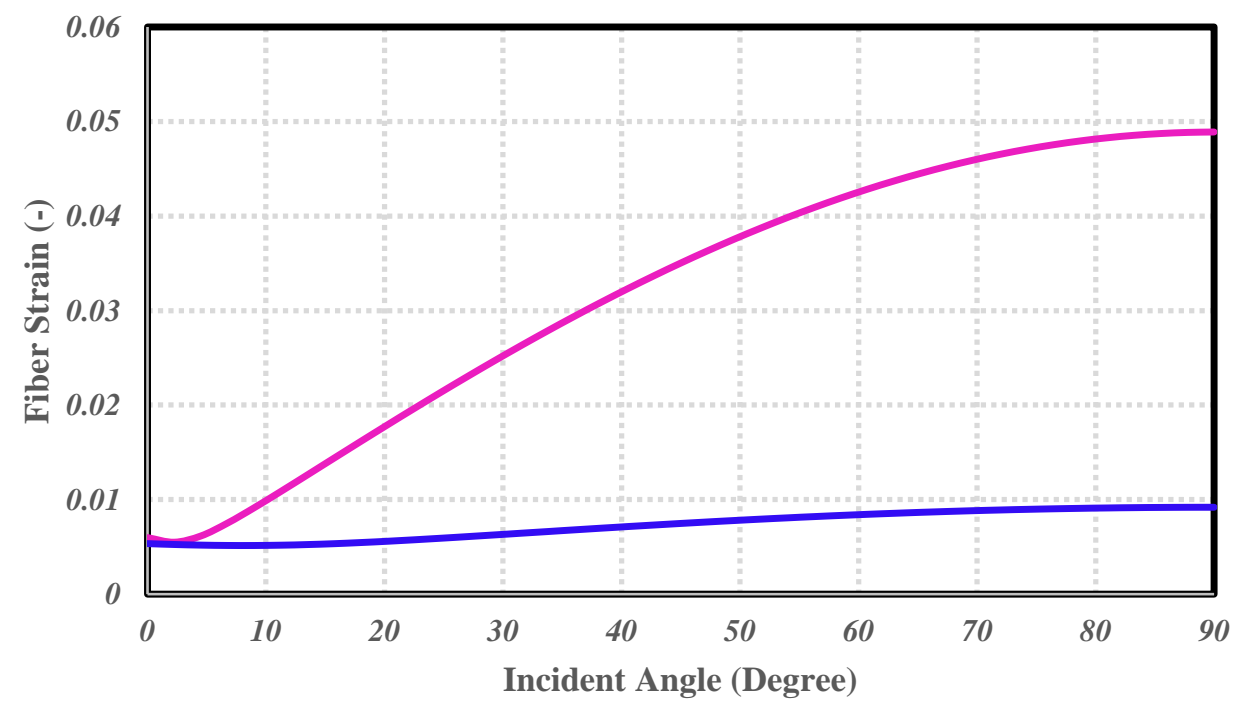

Scenario \#3 (Numerical Solution) - Scenario \#4 (Numerical Solution)

Figure 19. Investigation the effect of hard/soft Formation adjacent to the casing on the acoustic response of fiber (comparison between scenarios \#3 and \#4). 
https://doi.org/10.5194/se-2020-197

Preprint. Discussion started: 7 December 2020

(c) Author(s) 2020. CC BY 4.0 License.

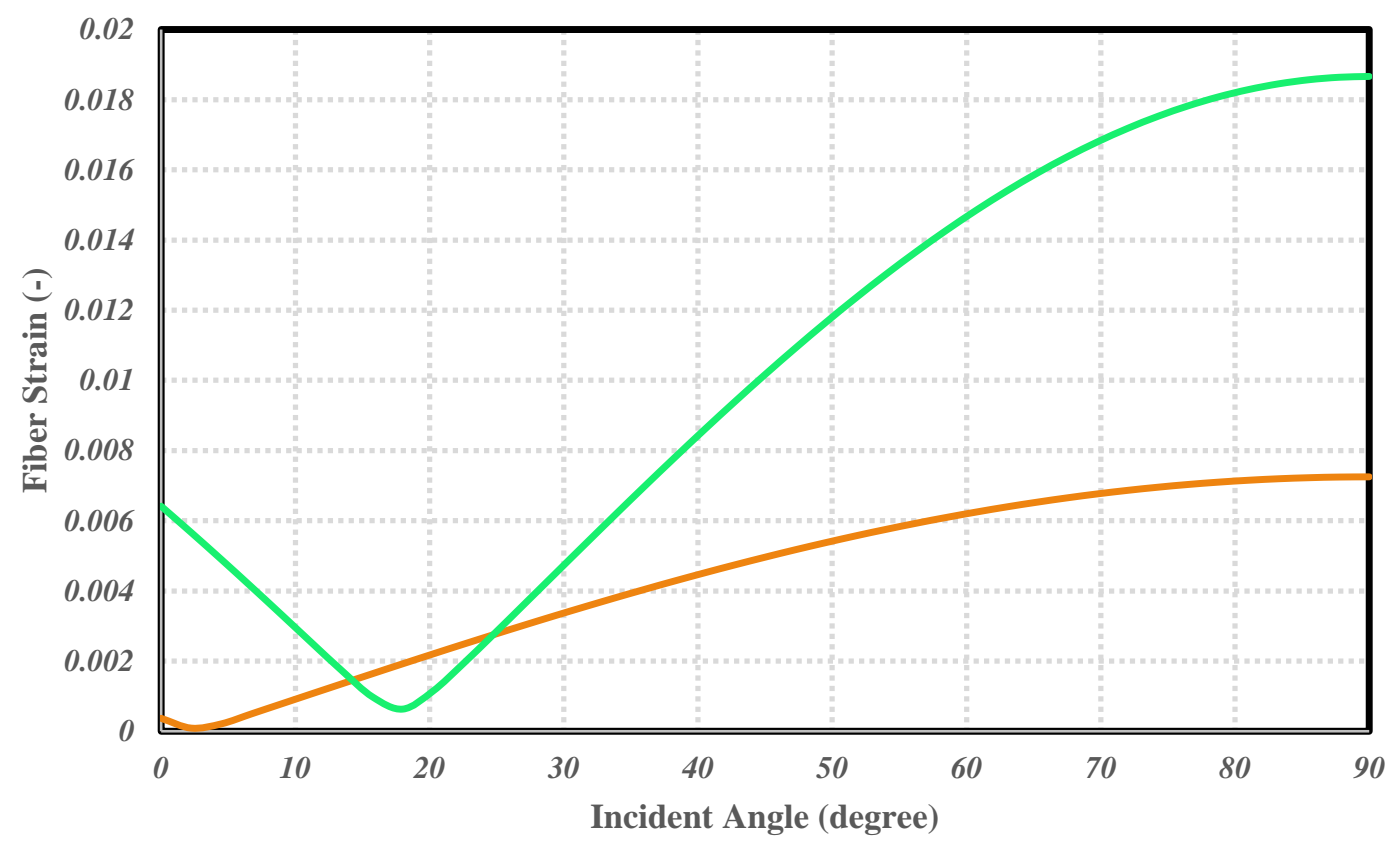

Scenario \#5 (Numerical Solution) —Scenario \#6 (Numerical Solution)

Figure 20. Investigation the effect of water on the acoustic response of fiber (comparison between scenarios \#5 and \#6.

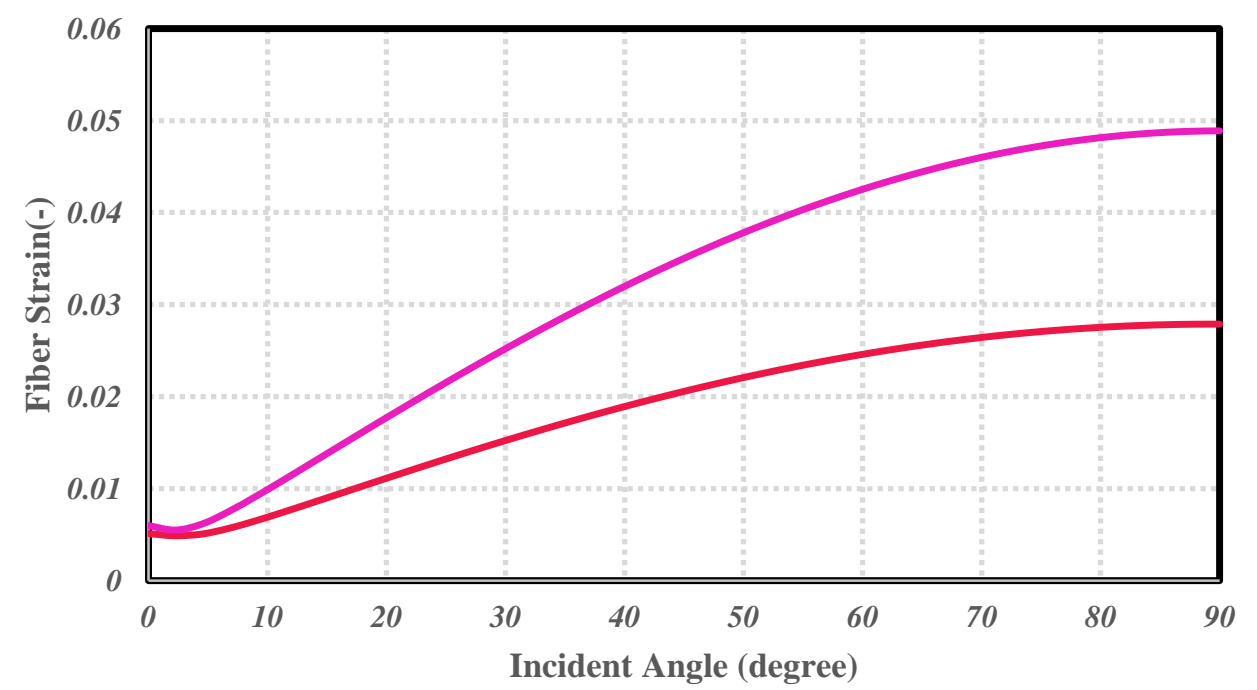

Scenario \#1 (Numerical Solution) - Scenario \#3 (Numerical Solution)

Figure 21. Investigation the number of layers on the acoustic response of fiber (comparison between scenarios \#1 and \#3). 
https://doi.org/10.5194/se-2020-197

Preprint. Discussion started: 7 December 2020

(c) Author(s) 2020. CC BY 4.0 License.

\section{(c) (i)}

\section{Discussion}

In this section, the modeling results are used to help understand the performance of a helically-wound fiber from a field study at the New Afton mine (Bellefleur et al., 2020). Figure 22 presents a comparison of raw field VSP data acquired on collocated straight and helically wound fiber-optic cables in a steeply-dipping $\left(70^{\circ}\right.$ from horizontal) deviated borehole located underground at the New Afton mine. Incident angles of seismic waves for data shown in Figure 22 range between 25 and 40 degrees. Both cables were placed inside steel drill rods (which were used as casing) and cemented in place with grout. The grout was circulated to the bottom of the borehole via a grout tube, and grout eventually reached surface from both inside and outside of the casing (drill rods), after which it was allowed to cure for one month prior to the VSP survey. Based on the aforenoted grout returns both within and outside the casing, it was assumed at the time that grout had filled both the casing and the casing-formation annulus; however, data collected during the survey (discussed below) suggests this may not have been the case.

270 The data were acquired with $1 \mathrm{~kg}$ of explosives fired in a $20 \mathrm{~m}$ deep shot hole at surface. An advanced DAS system providing higher signal-to-noise ratio (Carina system by Silixa) was used to record the seismic data. More details about instruments and acquisition parameters can be found in Bellefleur et al. (2020).

Our modeling results demonstrate that cementing of the helically-wound cable in hard rocks would not be detrimental to DAS measurements. Thus, cementing alone cannot explain the difference of amplitudes between straight and helically-wound cable.

Adding a thin layer of steel representing the casing also has minimal effects on DAS data..

Bellefleur et al. (2020) make the following observations and offer the following interpretations to explain them: Data recorded with the straight fiber-optic cable include several noisy traces at the locations indicated by the vertical arrows near the top-left corner of Figure 22a; in particular near traces 90 and 215, which coincide with fault zones as identified using wireline log data. Such noise is typical of un-cemented or poorly cemented casing and is caused by local casing resonance. Noisy traces are also observed at similar locations in the HWC (see vertical arrows near the top-left corner of Figure 22b), but resonance noise on those traces is not as strong as the straight fiber data. The HWC data are, however, strongly affected by tube waves between the two fault zones (see diagonal arrows in the left half of Figure 22b), which suggests the presence of liquid or incomplete cementing of the casing-formation annulus. Aside from the traces showing noise and resonance, the signal strength (fiber strain) of the linear fibre appears relatively good. As shown in Figure 22a, this dataset contains many events indicated with arrows and comprising direct P-and S-waves, many down-going waves (arrows $\mathrm{C}$ and $\mathrm{D}$ ), and reflected waves (indicated with white arrows). This suggests that the cement within the casing (i.e., encompassing the fibre cables) cured properly and contained no liquid, hence enabling a strong signal in the axial direction in response to the vertical component of the propagating seismic waves. Conversely, the HWC dataset showed a relatively weak response to the afore-noted events.

Based on the results obtained in this work, for which scenario \#5 (water-filled casing-formation annulus), the relatively weak response of the HWC dataset suggests that cementing emplacement and curing outside of casing was not effective for a significant portion of this borehole. The results obtained in scenario \#4 (soft rock formation in direct contact with casing) provide an additional explanation for poor signal quality; one which might be relevant over some intervals of the borehole. 
https://doi.org/10.5194/se-2020-197

Preprint. Discussion started: 7 December 2020

(c) Author(s) 2020. CC BY 4.0 License.

(c) (i)

This is suggested because Bellefleur et al. (2020) noted several weak and unstable intervals, and had to ream these intervals during drilling and logging operations, and leave drill rods in place over these intervals to prevent borehole collapse during logging operations. Scenario \#4 suggests that, even if the weak zone converged on the casing and achieved reasonably effective coupling, the soft nature of the rocks in these intervals would result in low fiber strains for the HWC.

The DAS dataset at New Afton, interpreted in the context of our modeling, serves as a practical demonstration of the extreme effects of surrounding media and coupling on HWC data quality. These results, and new scenarios simulated with the models developed in this work, can also be used to design more effective HWC systems in future field work.

\section{Conclusion}

We have developed a 2D analytical method to model dynamic strain generated in HWC due to plane compressional waves propagation in multilayer media. This analytical model is useful to model simple scenarios and can validate boundary conditions applied in 3D numerical model of complex scenarios. Strain values in helically-wound fiber optic cable estimated with our analytical method are comparable to those modeled with numerical simulations. We have investigated the effects of

305 the surrounding media on the axial and radial strains of HWC for six scenarios representative of realistic situation and based on parameters of DAS experiment conducted at the New Afton deposit, British Columbia. Based on our parameters, our analytical and numerical results show that the quality of cement (hard vs soft) between the casing and rock formation has a moderate effect on HWC data, with lower strain values observed for hard cement. However, having fully cured and emplaced cement inside and outside of casing is crucial to acquire decent signal from HWC. Effects of rock formation (hard vs soft) is more significant and can contribute to signal reduction on DAS data for HWC placed in soft rock formation. In all scenarios, effects are largest at higher incident angles (i.e. $90^{\circ}$ ). Presence of a water domain in the surrounding materials would make the fiber response more complicated owing to the combined effect of compressional and surface waves.

\section{Conflict of interest}

The authors know of no conflicts of interest with this publication.

\section{Acknowledgments}

The authors would like to thank the Petroleum Technology Research Centre and Mitacs for funding in support of the modeling components of this research. 


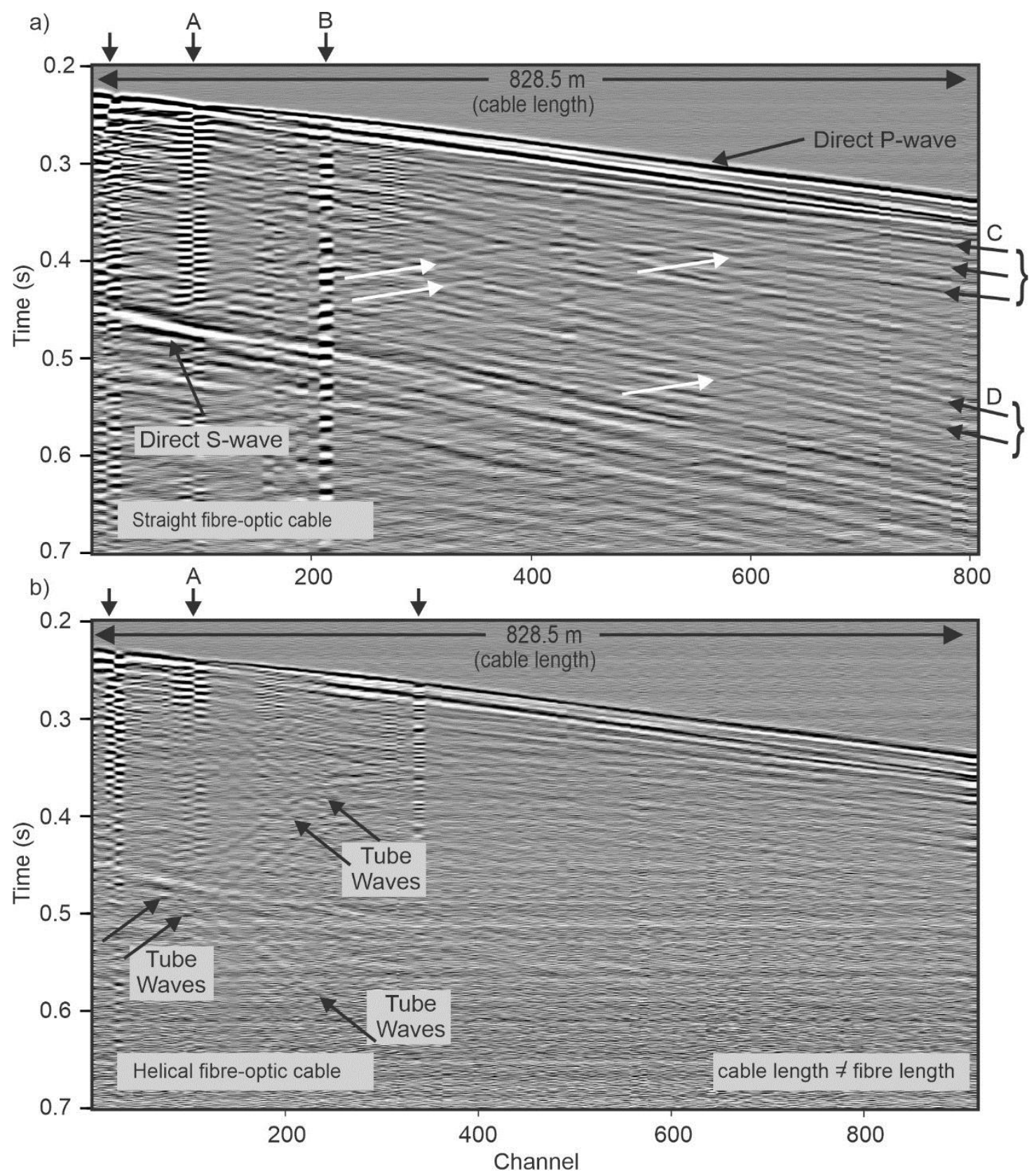

Figure 22. Comparison of field VSP data for a) straight fibre-optic cable and b) helically-wound fibre-optic cable. The helicallywound optical fibre has more channels than the straight fibre for the same length of cable due to the wrapping around the cable core (i.e., 925 channels for helically-wound cable versus 813 for the straight fibre-optic cable). Vertical arrows point to noisy channels indicating poor coupling. White arrows indicate up-going reflections. Arrows $C$ and $D$ point to events of the down-going wavefield with moveout of P-waves and S-waves, respectively. Events $D$ arrive before the direct $S$-wave and are likely the result of P-to-S conversion at a lithological contact or fault zone. The same display gain was used for a) and b). Horizontal banding observed across all channels is optical noise. Modified from Bellefleur et al (2020). 
https://doi.org/10.5194/se-2020-197

Preprint. Discussion started: 7 December 2020

(c) Author(s) 2020. CC BY 4.0 License.

(c) (i)

\section{Data Availability Statement}

The data that support the findings of this study are available from the corresponding author upon request.

\section{References}

Bellefleur, G., Schetselaar, E., Wade, D., White, D., Enkin, R., and Schmitt, D.R.: Vertical seismic profiling using distributed acoustic sensing (DAS) with scatter-enhanced fiber-optic cable at the $\mathrm{Cu}-\mathrm{Au}$ New Afton porphyry deposit, British Columbia, Canada; Geophysical Prospecting. 68, 313-333. https://doi.org/10.1111/1365-2478.12828, 2020.

Daley, T. M., Pevzner, R., Dou, S., Correa, J., Robertson, M., Tertyshnikov, K., Wood, T., Ajo-franklin, J., Urosevic, M., Popik, D., Gurevich, B., Miller, D. E., White, D., Robertson, M., Cocker, J., Strudley, A., Craven, M., Worth, K., Harris, K.: Advanced Monitoring Technology: DAS (Distributed Acoustic Sensing) at Otway and Aquistore. IEA Greenhouse Gas Monitoring Network. Edinburgh, Scotland, 2016.

Daley, T.M., Freifeld, B.M., Ajo-Franklin, J., Dou, S., Pevzner, R., Shulakova, V., Kashikar, S., Miller, D.E., Goetz, J., Henninges, J. and Lueth, S.: Field testing of fiber-optic distributed acoustic sensing (DAS) for subsurface seismic monitoring. The Leading Edge, 32(6), pp.699-706, 2013.

Den Boer, J.J., Mateeva, A.A., Pearce, J.G., Mestayer, J.J., Birch, W., Lopez, J.L., Hornman, J.C. and Kuvshinov, B.N., Shell

Oil Co.: Detecting broadside acoustic signals with a fiber optical distributed acoustic sensing (DAS) assembly. U.S. Patent 9,766,119, 2017.

Folds, D.L. and Loggins, C.D.: Transmission and reflection of ultrasonic waves in layered media. The Journal of the Acoustical Society of America, 62(5), pp.1102-1109, 1977.

Harris, K., White, D., Melanson, D., Samson, C., and Daley, T.: Feasibility of time-lapse VSP monitoring at the Aquistore $\mathrm{CO}_{2}$ storage site using a distributed acoustic sensing system. International Journal of Greenhouse Gas Control, 50, 248260. http://doi.org/10.1016/j.ijggc.2016.04.016, 2016.

Hartog, A.H.: An introduction to distributed optical fibersensing. CRC Press, Boca Raton, 472 p, 2018.

Hornman, K.: Distributed Acoustic Sensing Cable for Surface Seismic. EAGE E-Lecture. Video retrieved from https://www.youtube.com/watch?v=nCv5qytW1Y4, 2015.

355 Kuvshinov, B.N.: Interaction of helically wound fiber-optic cables with plane seismic waves. Geophysical Prospecting, 64(3), pp.671-688, 2016.

Miah, K., and Potter, D.K.: A review of hybrid fiber-optic distributed simultaneous vibration and temperature sensing technology and its geophysical applications. Sensors 2017, 17, 2511; doi:10.3390/s17112511, 2017.

Miller, D.E., Daley, T.M., White, D., Freifeld, B.M., Robertson, M., Cocker, J. and Craven, M.: Simultaneous acquisition of distributed acoustic sensing VSP with multi-mode and single-mode fiber-optic cables and 3C-geophones at the Aquistore CO2 storage site. CSEG Recorder, 41(6), 2016. 
https://doi.org/10.5194/se-2020-197

Preprint. Discussion started: 7 December 2020

(c) Author(s) 2020. CC BY 4.0 License.

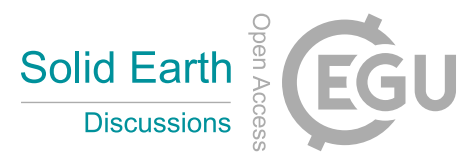

(c) (1)

Mollahasani Madjdabadi, B.: Experimental Evaluation of a Distributed Fiber Optic Sensor for Mining Application, Doctoral dissertation, UWSpace, 2016.

Ranjan, P. and McColpin, G.: Fiber-Optic Sensing: Turning the Lights on Downhole. The Digital Oil Field, pp.34-37, 2013.

365 Riedel, M., Cosma, C., Enescu, N., Koivisto, E., Komminaho, K., Vaittinen, K., and Malinowski, M.: Underground vertical seismic profiling with conventional and fiber-optic systems for exploration in the Kylylahti polymetallic mine, eastern Finland. Minerals, 8, 538. https://doi.org/10.3390/min8110538, 2018.

370

375

380

385 


\section{Appendix A. A 2-D analytical approach to determine the dynamic strain of helically wound cable}

400 For this two-dimensional (2-D) model, it is assumed that the seismic source is located far away from the location of the HWC. This assumption results in a plane wave propagating in the in $\mathrm{X}-\mathrm{Z}$ plane (Figure A.1). The governing equation for a plane sinusoidal wave in two-dimensional space is defined by following potential function:

$$
\varphi=A_{0} \exp \left(i\left(K_{x} * x+K_{z} * z-\omega t\right)\right)
$$

Where $A_{0}$ is the initial amplitude of the seismic wave, $k_{x}$ is the wavenumber in the $x$ direction $(\mathrm{rad} / \mathrm{m}), K_{z}$ is the wavenumber in the $z$ direction $(\mathrm{rad} / \mathrm{m}), \omega$ is the angular frequency $(\mathrm{rad} / \mathrm{s})$, and $t$ is the time (s).

405 The following relationship exists between displacement (u) and the potential function:

$$
u=\nabla_{\varphi}
$$

In order to define the compressional wave propagation equation as a function of incident angle (denoted by $\gamma$ ), we define the direction of ray path as a function of wave number (Fig. A.1).

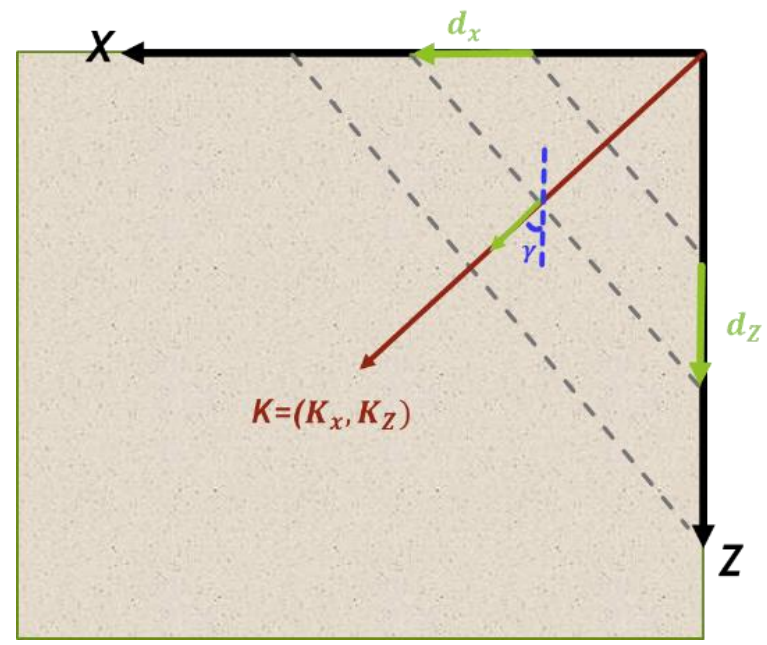

Figure A.1: The arrow is used to denote a ray and the dashed line is used to denote a wavefront. $K$ indicates the direction of the ray. The angle $\gamma$ is the incident angle

According to Fig. A.2, the wavenumber can be defined as follows: 


$$
k=k 0(-\sin (\gamma),-\cos (\gamma))
$$

Where $k 0$ is the initial wavenumber related to the initial source and $\gamma$ is the incident angle the wavefront relative to the $\mathrm{z}$-axis.

415 In the above equation, the negative signs represent propagation in the negative quadrant of the coordinate system.

Under ideal assumptions (e.g., uniform density, uniform tension, no resistance to motion, small deflection, etc.), one can show that the displacement $(u)$ satisfies the two-dimensional semi-infinite wave equation with free ends:

$$
u_{t t}=C^{2} \nabla^{2} u=C^{2}\left(u_{x x}+u_{y y}\right)
$$

Where $C$ is a fixed non-negative real coefficient, and $u_{t t}$ is $\frac{\partial^{2} u}{\partial t^{2}}$

Assuming perfect plane wave propagation, stresses generated inside the medium far away from the acoustic source are obtained with the following equations:

$$
\begin{aligned}
& \sigma_{x x}=(\lambda+2 \mu) \frac{\partial u_{x}}{\partial x}+\lambda \frac{\partial u_{z}}{\partial z} \\
& \sigma_{z z}=(\lambda+2 \mu) \frac{\partial u_{z}}{\partial z}+\lambda \frac{\partial u_{x}}{\partial x}
\end{aligned}
$$

Where $\mu$ and $\lambda$ are shear modulus and lame constant, and $\sigma_{x x}$ and $\sigma_{z z}$ are stresses in $\mathrm{x}$ and $\mathrm{z}$ directions, respectively.

By substituting equations A.1 and A.2 into A.5 and A.6:

$$
\begin{aligned}
& \sigma_{x x}=A_{0}\left((\lambda+2 \mu)\left(k_{x}^{2}\right)+\lambda\left(k_{z}^{2}\right)\right) \exp \left(i\left(k_{x} * x+k_{z} * z-\omega t\right)\right) \\
& \sigma_{z z}=A_{0}\left((\lambda+2 \mu)\left(k_{z}^{2}\right)+\lambda\left(k_{x}^{2}\right)\right) \exp \left(i\left(k_{x} * x+k_{z} * z-\omega t\right)\right)
\end{aligned}
$$

A plane acoustic wave is assumed to strike a multilayered media as shown in Figure A.2. The compressional wave originates from a source located in layer 1 and proceeds through the intervening layers to emerge into layer $n+1$. It should be noted that

425 the HWC is in layer $\frac{n}{2}+1$. The layers are assumed to have infinite extent in the $\mathrm{z}$ direction, and the plane wave incident upon layer 1 is assumed to lie in the X-Z plane, making the problem two-dimensional. In effect, concentric layers that would exist around a borehole in the true three-dimensional problem are represented as planar layers in this two-dimensional representation. 


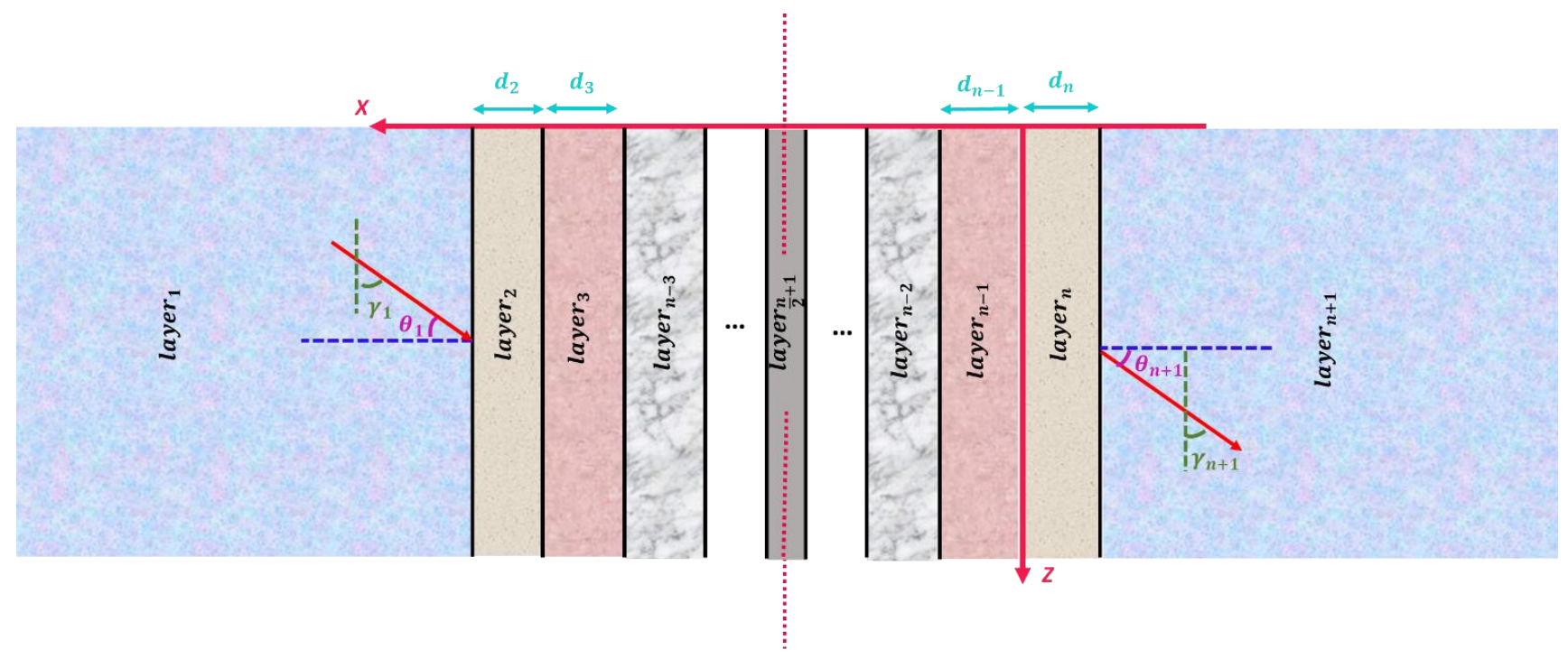

430 Figure A.2. Propagation of compressional waves from source (layer 1) to layer $\mathbf{n}+1$ (After Folds and Loggins, 1977). In the scenario considered in this work, layer $\mathbf{n} / 2+1$ represents the borehole, which is a plane of symmetry in this $2 \mathrm{D}$ plane-strain model.

When the stratified medium consists of parallel solid plates, the equations for one section must be related to those of the adjacent section by proper boundary conditions used at interfaces between layers to satisfy continuity of normal $\left(\sigma_{x x}\right)$ and shear stresses $\left(\sigma_{x z}\right)$, and normal $\left(u_{x}\right)$ and tangential displacements $\left(u_{z}\right)$. Each layer (with layer number denoted by the index

$\left.{ }^{l}\right)$ is considered linear elastic and isotropic if the following boundary conditions are satisfied:

$$
\begin{aligned}
& u_{x}^{l}=u_{x}^{l+1} \\
& u_{z}^{l}=u_{z}^{l+1} \\
& \sigma_{x x}^{l}=\sigma_{x x}^{l+1} \\
& \sigma_{x z}^{l}=\sigma_{x z}^{l+1}
\end{aligned}
$$

At any layer, the displacements and stresses are given in terms of the following potential function [After 13]:

$$
\varphi_{l}=\left(A_{l} \exp \left(i \alpha_{l} x\right)+B_{l} \exp \left(-i \alpha_{l} x\right)\right) \exp \left(i\left(\beta_{l} z-\omega t\right)\right)
$$

Where $\varphi_{l}$ is the potential function for longitudinal waves, $\alpha_{l}$ is the $\mathrm{x}$ component of wavenumber, $\beta$ is the $\mathrm{z}$ component of wavenumber, $A_{l}$ is the amplitude of incident wave, and $B_{l}$ the amplitude of reflected wave.

In equation A.13, $\alpha_{l}=k_{l} \sin \gamma_{l}$ and $\beta_{l}=k_{l} \cos \gamma_{l}$ are the $\mathrm{x}$ and $\mathrm{z}$ components of the wave vector, respectively. It should be noted that $k_{l}$ is the wavenumber in layer $l$.

As shown in Figure A.2, the angle of the wave vector with the normal of the interface is $\theta$. The following relationship exists between the angle of the wavefront relative to the $z$-axis and the interface normal vector: 
$\gamma_{1}=90-\theta_{1}$

This yields:

$$
\begin{aligned}
& \alpha_{1}=\mathrm{k}_{1} \sin \left(\gamma_{1}\right)=\mathrm{k}_{1} \sin \left(90-\theta_{1}\right)=\mathrm{k}_{1} \cos \left(\theta_{1}\right) \\
& \beta_{1}=\mathrm{k}_{1} \cos \left(\gamma_{1}\right)=\mathrm{k}_{1} \cos \left(90-\theta_{1}\right)=\mathrm{k}_{1} \sin \left(\theta_{1}\right)
\end{aligned}
$$

Clearly, based on Snell's equation, we must have:

$$
\mathrm{k}_{1} \sin \theta_{1}=\mathrm{k}_{2} \sin \theta_{2}=\cdots=\mathrm{k}_{\mathrm{n}-1} \sin \theta_{\mathrm{n}-1}=\mathrm{k}_{\mathrm{n}} \sin \theta_{\mathrm{n}}
$$

445 As shown in equation A.13, $\beta$ is the same (according to Snell's law) for all layers. $\theta_{l}$ is the angle between the direction of the plane wave in layer $l$ and the normal of interface.

At any point inside or on the boundaries of layer $l$, the displacements and stresses are defined as follows:

$$
\begin{aligned}
& \mathrm{u}_{\mathrm{x}}^{\mathrm{l}}=\frac{\partial \varphi_{\mathrm{l}}}{\partial \mathrm{x}} \\
& \mathrm{u}_{\mathrm{z}}^{\mathrm{l}}=\frac{\partial \varphi_{\mathrm{l}}}{\partial \mathrm{z}} \\
& \sigma_{\mathrm{xx}}^{\mathrm{l}}=\lambda\left(\frac{\partial \mathrm{u}_{\mathrm{x}}^{1}}{\partial \mathrm{x}}+\frac{\partial \mathrm{u}_{\mathrm{z}}^{1}}{\partial \mathrm{z}}\right)+2 \mu \frac{\partial \mathrm{u}_{\mathrm{x}}^{1}}{\partial \mathrm{x}} \\
& \sigma_{\mathrm{xz}}^{\mathrm{l}}=\mu\left(\frac{\partial \mathrm{u}_{\mathrm{x}}^{\mathrm{l}}}{\partial \mathrm{z}}+\frac{\partial \mathrm{u}_{\mathrm{z}}^{\mathrm{l}}}{\partial \mathrm{x}}\right)
\end{aligned}
$$

The displacements and stresses on the right-side interface of layer $\mathrm{n}+1$ are obtained by substituting equation A.13 into equations A.20 and A.21 and using $l=n, x=h_{n}+\epsilon$ (where $\epsilon$ is infinitesimal):

$$
h_{n}=d_{1}+d_{2}+\cdots+d_{n-1}+d_{n}
$$

450 This yields:

$$
\left[\begin{array}{c}
\sigma_{x x}^{n+1} \\
\sigma_{x z}^{n+1}
\end{array}\right]=\left[\begin{array}{cc}
G_{n+1} N_{n+1} & G_{n+1} M_{n+1} \\
R_{n+1} N_{n+1} & -R_{n+1} M_{n+1}
\end{array}\right]\left[\begin{array}{c}
A_{n+1} \\
B_{n+1}
\end{array}\right]
$$

with

$$
\begin{aligned}
& N_{n+1}=\exp \left(i\left(\alpha_{n+1} h_{n}+\beta * z\right)\right) \\
& M_{n+1}=\exp \left(i\left(\beta * z-\alpha_{n+1} h_{n}\right)\right) \\
& R_{n+1}=-2 \mu_{n+1} \alpha_{n+1} \beta
\end{aligned}
$$




$$
G_{n+1}=\left[\left(\lambda_{n+1}+2 \mu_{n+1}\right)\left(-\alpha_{n+1}{ }^{2}\right)+\lambda_{n+1}\left(-\beta^{2}\right)\right]
$$

Now just inside the $\mathrm{n}^{\text {th }}$ layer (e.g., at $=h_{n}-\epsilon$ ), the stresses are given as follows:

$$
\left[\begin{array}{c}
\sigma_{x x}^{n} \\
\sigma_{x z}^{n}
\end{array}\right]=\left[\begin{array}{cc}
G_{n} N_{n} & G_{n} M_{n} \\
R_{n} N_{n} & -R_{n} M_{n}
\end{array}\right]\left[\begin{array}{l}
A_{n} \\
B_{n}
\end{array}\right]
$$

with

$$
\begin{aligned}
& N_{n}=\exp \left(i\left(\alpha_{n} h_{n}+\beta * z\right)\right) \\
& M_{n}=\exp \left(i\left(\beta * z-\alpha_{n} h_{n}\right)\right) \\
& R_{n}=-2 \mu_{n} \alpha_{n} \beta \\
& G_{n}=\left[\left(\lambda_{n}+2 \mu_{n}\right)\left(-\alpha_{n}{ }^{2}\right)+\lambda_{n}\left(-\beta^{2}\right)\right]
\end{aligned}
$$

Values in equation A.28 were obtained by substituting $\mathrm{n}=1$ in equations A.17 and A.18.

455 Solving for the matrix of amplitude coefficients $\left(A_{n+1}\right.$ and $\left.B_{n+1}\right)$ :

$$
\left[\begin{array}{l}
A_{n+1} \\
B_{n+1}
\end{array}\right]=\left[\begin{array}{cc}
1 /\left(2 G_{n+1} N_{n+1}\right) & 1 /\left(2 R_{n+1} N_{n+1}\right) \\
1 /\left(2 G_{n+1} M_{n+1}\right) & -1 /\left(2 R_{n+1} M_{n+1}\right)
\end{array}\right]\left[\begin{array}{c}
\sigma_{x x}^{n+1} \\
\sigma_{x z}^{n+1}
\end{array}\right]
$$

Based on the boundary conditions described in A.11 and A.12, and substituting equation A.28 into the right hand side of equation A.29, the following equation is obtained:

$$
\left[\begin{array}{l}
A_{n+1} \\
B_{n+1}
\end{array}\right]=\left[\begin{array}{cc}
1 /\left(2 G_{n+1} N_{n+1}\right) & 1 /\left(2 R_{n+1} N_{n+1}\right) \\
1 /\left(2 G_{n+1} M_{n+1}\right) & -1 /\left(2 R_{n+1} M_{n+1}\right)
\end{array}\right]\left[\begin{array}{cc}
G_{n} N_{n} & G_{n} M_{n} \\
R_{n} N_{n} & -R_{n} M_{n}
\end{array}\right]\left[\begin{array}{c}
A_{n} \\
B_{n}
\end{array}\right]
$$

As a result, the following relationship exists between the amplitude of layer $\mathrm{n}+1$ and layer $\mathrm{n}$ :

$$
\begin{aligned}
& {\left[\begin{array}{l}
A_{n+1} \\
B_{n+1}
\end{array}\right]=\left[\begin{array}{ll}
\left(N_{n} / 2 N_{n+1}\right)\left(G_{n} / G_{n+1}+R_{n} / R_{n+1}\right) & \left(M_{n} / 2 N_{n+1}\right)\left(G_{n} / G_{n+1}-R_{n} / R_{n+1}\right) \\
\left(N_{n} / 2 M_{n+1}\right)\left(G_{n} / G_{n+1}-R_{n} / R_{n+1}\right) & \left(M_{n} / 2 M_{n+1}\right)\left(G_{n} / G_{n+1}+R_{n} / R_{n+1}\right)
\end{array}\right]} \\
& \times\left[\begin{array}{l}
A_{n} \\
B_{n}
\end{array}\right]
\end{aligned}
$$

The transformation matrix is named as $E_{l}$ :

460 By considering:

$$
\begin{aligned}
& \left(N_{n} / N_{n+1}\right)=\exp \left(i h_{n}\left(\alpha_{n}-\alpha_{n+1}\right)\right)=S_{n+1} \\
& \left(N_{n} / M_{n+1}\right)=\exp \left(i h_{n}\left(\alpha_{n}+\alpha_{n+1}\right)\right)=V_{n+1}
\end{aligned}
$$




$$
\begin{aligned}
& \left(M_{n} /_{N_{n+1}}\right)=\exp \left(-i h_{n}\left(\alpha_{n}+\alpha_{n+1}\right)\right)=W_{n+1} \\
& \left(M_{n} /_{M_{n+1}}\right)=\exp \left(-i h_{n}\left(\alpha_{n}-\alpha_{n+1}\right)\right)=J_{n+1}
\end{aligned}
$$

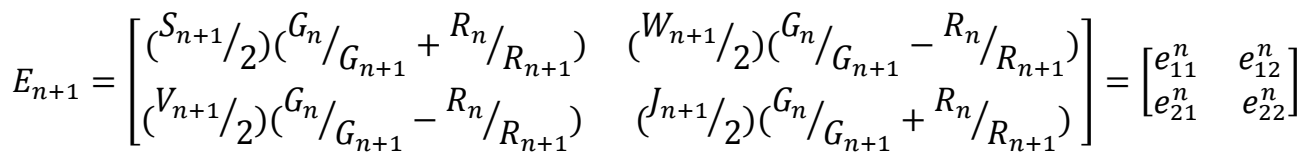

$$
\left[\begin{array}{l}
A_{n+1} \\
B_{n+1}
\end{array}\right]=E_{n+1}\left[\begin{array}{l}
A_{n} \\
B_{n}
\end{array}\right]
$$

Application of the boundary condition at $x=h_{n}$ equates the velocities and stresses in layer $\mathrm{n}$ with those in layer $\mathrm{n}+1$ at the interface, and the process used above can be repeated for each of the $n-1$ layers between $n+1$ and 1 . Because of this, we can now write:

$$
\left[\begin{array}{l}
A_{n+1} \\
B_{n+1}
\end{array}\right]=\left[\begin{array}{lll}
E_{n+1} E_{n} E_{n-1} & \cdots & E_{3} E_{2}
\end{array}\right]\left[\begin{array}{l}
A_{1} \\
B_{1}
\end{array}\right]=\left[\begin{array}{ll}
F_{11} & F_{12} \\
F_{21} & F_{22}
\end{array}\right]\left[\begin{array}{l}
A_{1} \\
B_{1}
\end{array}\right]
$$

We have assumed that the layer $n+1$ extends to infinity, which results in the fact that there are no reflections inside layer $n+1$ $\left(B_{n+1}=0\right)$. In equation A.42, $A_{1}$ is the amplitude of the wave generated by the seismic source and it is a known parameter. By having $B_{n+1}=0$ and $A_{1}$, we can estimate $B_{1}$ and $A_{n+1}$ with the following equations:

$$
\begin{aligned}
& B_{1}=-\left(F_{21} / F_{22}\right) A_{1} \\
& A_{n+1}=\left(F_{11}\right) A_{1}+\left(F_{12}\right) B_{1}
\end{aligned}
$$

By knowing $A_{1}$ and $B_{1}$, it is possible to calculate the amplitude of incident and reflected waves inside each layer. As a result, by replacing these values inside equation A.13, we are able to calculate stresses and displacements for each layer. Strains can be calculated directly from displacements with the following relationships:

$$
\begin{gathered}
\varepsilon_{\mathrm{xx}}^{\mathrm{n}}=\partial \mathrm{u}_{\mathrm{xx}}^{\mathrm{n}} / \partial \mathrm{x} \\
\varepsilon_{\mathrm{zz}}^{\mathrm{n}}=\partial \mathrm{u}_{\mathrm{zz}}^{\mathrm{n}} / \partial \mathrm{z}
\end{gathered}
$$

470 Following the two-dimensional dynamic strain response on the HWC as represented by the coordinate system in the righthand side of Fig. $2 \mathrm{~b}, \varepsilon_{x x}$ is equal to radial strain $\left(\varepsilon_{\mathrm{rr}}\right)$ and $\varepsilon_{z z}$ is equal to longitudinal strain $\left(\varepsilon_{\|}\right)$(Fig. 2b). As a result, fiber strain $\left(\varepsilon_{\mathrm{zz}}\right)$ is calculated as follows: 
https://doi.org/10.5194/se-2020-197

Preprint. Discussion started: 7 December 2020

(C) Author(s) 2020. CC BY 4.0 License.

$\varepsilon_{\mathrm{zz}_{(\text {Fiber })}}=\varepsilon_{\|_{(\text {Cable })}} \cos ^{2} \alpha+\varepsilon_{\text {rr (Cable) }} \sin ^{2} \alpha$ 